National Bureau of Standards

Library, E-01 Admin. Bldg.

OCT 61981

19129

QC

100

45753

NBS TECHNICAL NOTE 927

U.S. DEPARTMENT OF COMMERCE / National Bureau of Standards

\title{
Development of \\ Dynamic Calibration Methods for Pogo Pressure Transducers
}




\section{NATIONAL BUREAU OF STANDARDS}

The National Bureau of Standards ${ }^{1}$ was established by an act of Congress March 3, 1901. The Bureau's overall goal is to strengthen and advance the Nation's science and technology and facilitate their effective application for public benefit. To this end, the Bureau conducts research and provides: (1) a basis for the Nation's physical measurement system, (2) scientific and technological services for industry and government, (3) a technical basis for equity in trade, and (4) technical services to promote public safety. The Bureau consists of the Institute for Basic Standards, the Institute for Materials Research, the Institute for Applied Technology, the Institute for Computer Sciences and Technology, and the Office for Information Programs.

THE INSTITUTE FOR BASIC STANDARDS provides the central basis within the United States of a complete and consistent system of physical measurement; coordinates that system with measurement systems of other nations; and furnishes essential services leading to accurate and uniform physical measurements throughout the Nation's scientific community, industry, and commerce. The Institute consists of the Office of Measurement Services, the Office of Radiation Measurement and the following Center and divisions:

Applied Mathematics - Electricity - Mechanics - Heat - Optical Physics - Center for Radiation Research: Nuclear Sciences; Applied Radiation - Laboratory Astrophysics ${ }^{2}$ - Cryogenics ${ }^{2}$ - Electromagnetics ${ }^{2}$ - Time and Frequency ${ }^{2}$.

THE INSTITUTE FOR MATERIALS RESEARCH conducts materials research leading to improved methods of measurement, standards, and data on the properties of well-characterized materials needed by industry, commerce, educational institutions, and Government; provides advisory and research services to other Government agencies; and develops, produces, and distributes standard reference materials. The Institute consists of the Office of Standard Reference Materials, the Office of Air and Water Measurement, and the following divisions:

Analytical Chemistry - Polymers - Metallurgy - Inorganic Materials — Reactor Radiation - Physical Chemistry.

THE INSTITUTE FOR APPLIED TECHNOLOGY provides technical services to promote the use of available technology and to facilitate technological innovation in industry and Government; cooperates with public and private organizations leading to the development of technological standards (including mandatory safety standards), codes and methods of test; and provides technical advice and services to Government agencies upon request. The Institute consists of the following divisions and Centers:

Standards Application and Analysis - Electronic Technology - Center for Consumer Product Technology: Product Systems Analysis; Product Engineering - Center for Building Technology: Structures, Materials, and Life Safety; Building Environment; Technical Evaluation and Application - Center for Fire Research: Fire Science; Fire Safety Engineering.

THE INSTITUTE FOR COMPUTER SCIENCES AND TECHNOLOGY conducts research and provides technical services designed to aid Government agencies in improving cost effectiveness in the conduct of their programs through the selection, acquisition, and effective utilization of automatic data processing equipment; and serves as the principal focus within the executive branch for the development of Federal standards for automatic data processing equipment, techniques, and computer languages. The Institute consists of the following divisions:

Computer Services — Systems and Software - Computer Systems Engineering - Information Technology.

THE OFFICE FOR INFORMATION PROGRAMS promotes optimum dissemination and accessibility of scientific information generated within NBS and other agencies of the Federal Government; promotes the development of the National Standard Reference Data System and a system of information analysis centers dealing with the broader aspects of the National Measurement System; provides appropriate services to ensure that the NBS staff has optimum accessibility to the scientific information of the world. The Office consists of the following organizational units:

Office of Standard Reference Data - Office of Information Activities - Office of Technical Publications - Library - Office of International Relations - Office of International Standards.

${ }^{1}$ Headquarters and Laboratories at Gaithersburg, Maryland, unless otherwise noted; mailing address Washington, D.C. 20234.

" Located at Boulder, Colorado 80302 . 
John S. Hilten, Paul S. Lederer, Carol F. Vezzetti, and

J. Franklin Mayo-Wells

Electronic Technology Division

Institute for Applied Technology

National Bureau of Standards

Washington, D.C. 20234

Sponsored by:

National Aeronautics and Space Administration

G. C. Marshall Space Flight Center

Huntsville, Alabama 35812

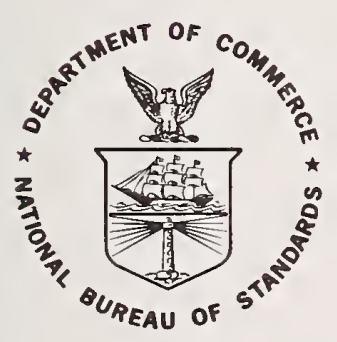

U.S. DEPARTMENT OF COMMERCE, Elliot L. Richardson, Secretary

Edward O. Vetter, Under Secretary

Dr. Betsy Ancker-Johnson, Assistant Secretary for Science and Technology

5 NATIONAL BUREAU OF STANDARDS, Ernest Ambler, Acting Director

Issued November 1976 
National Bureau of Standards Technical Note 927

Nat. Bur. Stand. (U.S.), Tech. Note 927, 58 pages (Nov. 1976)

CODEN: NBTNAE

U.S. GOVERNMENT PRINTING OFFICE

WASHINGTON: 1976

For sale by the Superintendent of Documents, U.S. Government Printing Office, Washington, D.C. 20402 (Order by SD Catalog No. C13.46:927). Stock No. 003-003-

Price $\$ 1.15$

(Add 25 percent additional for other than U.S. mailing). 
The work described was performed as a task within the InterAgency Transducer Project. This is a continuing project for the development of calibration and evaluation techniques for electromechanical transducers, and is supported by the National Bureau of Standards and a number of other Government agencies. This task was largely funded by the National Aeronautics and Space Administration through the G. C. Marshall Space Flight Center under order number H-92100A.

\author{
Paul S. Lederer \\ Acting Chief \\ Components and Applications Section
}





\section{DEVELOPMENT OF DYNAMIC CALIBRATION METHODS \\ FOR POGO PRESSURE TRANSDUCERS}

\section{CONTENTS}

1. Introduction ................... 1

2. Experimental Development ............. 2

2.1 Background: Discussion of Calibration Using Open-Tube Source ............. 2

2.2 Development of Closed-Tube Source ......... 3

2.2.1 Pressure Halving in a Closed-Tube ...... 3

2.2.2 Inertial Effects ........... 4

2.2.3 Column Design and Construction ....... 7

2.2.4 Working Fluids . . . . . . . . . . 7

2.2.5 Effect of Variations in Bias Pressure . . . . 8

2.2.6 Source Repeatability ........... 9

2.3 Development of Windmill Source .......... 9

2.4 Other Source Designs Using Working Liauids . . . . . 12

2.4.1 Extensions of the Open-Tube Source ...... 12

2.4.2 0ther Source Schemes.......... 13

3. Calibration ......................... 13

3.1 Filling the Column ............... 13

3.1.1 Filling Procedure ........... 13

3.1.2 Resonance Measurements .......... 15

3.2 Calibration Procedures for Closed-Tube Sources .... 16

3.2.1 Calibration on Vibration Exciter....... 16

3.2.2 Calibration of Windmill Apparatus ...... 17

3.3 Error Analysis . . . . . . . . . . . 20

4. Measurements on Seven Pogo Pressure Transducers . . . . . 21

4.1 Frequency-Response Measurements . . . . . . . . 21

4.2 Phase-Shift Measurements . . . . . . . . . 23

4.3 Repeatability Measurements . . . . . . . . . . 24

4.4 Acceleration Linearity Measurements . . . . . . . . 24

4.5 Vibration Response Measurements . . . . . . . . 24

5. Conclusions ................ . . . . 24

6. Recommendations ............. . . 25

7. Acknowledgment ............. . . 25

8. References................ 26

\section{LIST OF TABLES}

Table 1: Calculated Pressure Capability of a Closed-Tube LiquidColumn Source for Two Working Fluids at Constant

Displacement . . . . . . . . . . . 27

Table 2: Effect of Bias-Pressure Variation on Transducer Response with Silicone $0 i l$ as the Working Fluid . . 28 
Table 3: Closed-Tube Source Repeatability as Determined with Two Transducers . . . . . . . . . . . . . 29

Table 4: Resonance Frequency as a Function of Closed-Tube

Column Bias Pressure for Mercury and Silicone $0 \mathrm{il}$

Table 5: Factors Contributing to Estimated Transducer

Cal ibration Error

Table 6: Phase Shift Between Pressure and Transducer-0utput Waveforms for Transducer 537 on Windmill Apparatus

Table 7: Acceleration Linearity Measurements for Two

Transducers . . . . . . . . . . . . . 33

Table 8: Vibration Response Measurements for Two Transducers $\quad 34$

\section{LIST OF FIGURES}

Figure 1: Two Source Columns Used in Early Experiments . . . .

Figure 2: Transducer Output (mV rms) at Constant Acceleration

Plotted as a Function of Frequency $(\mathrm{Hz})$ for Two

Transducer Locations and for Open- and Closed-Tube

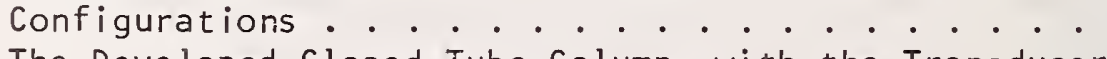

Figure 3: The Developed Closed-Tube Column, with the Transducer

(A) at the Top, or Free End . . . . . . . . . 37

Figure 4: Engineering Sketch of Closed-Tube Column

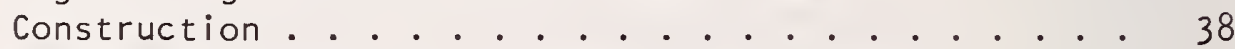

Figure 5: Engineering Sketch of Two-Piece Fixture Used to Mount the Column (Shown in Figure 3) Inverted . . . . . 39

Figure 6: Closed-Tube Column with Provisions for Mounting a

Test Transducer (A) at Each End for an Experimental

Investigation of Inertial Effects as Described in

the Text $\cdot \dot{0} \cdot \dot{0} \cdot \dot{0} \cdot \dot{0} \cdot \cdot \cdot \cdot \cdot \cdot \cdot \cdot \cdot \dot{0} \cdot \dot{0}$

Figure 7: Transducer Sensitivity (mV/kPa) as a Function of Added Mass ( $\mathrm{g}$ ) and of a Quantity (g) Equal to the Sum of the Added Mass and One-Half the Distributed Mass . . . .

Figure 8: Apparatus Used in the Calibration of Pressure

Transducers for Pogo Measurements . . . . . . . . 42

Figure 9: The Windmill Source, Consisting of the Closed-Tube

Column Mounted on the Windmill Apparatus . . . . . . . 43

Figure 10: Close-Up View of the Rotating Assembly of the

Windmill Apparatus.

Figure 11: Photographs of Oscilloscope Traces of Waveforms from

a Test Transducer Calibrated on the Windmill Source

and on the Oscillating Source at Several Frequencies

Figure 12: Schematic Elevation of Apparatus Used to Fill

Closed-Tube Column . . . . . . . . . . . . . .

Figure 13: Column Resonance Frequency ( $\mathrm{Hz}$ ) Plotted as a Function of Bias Pressure (MPa) for Mercury and Silicone 0 il as Working Liquids

Figure 14: Transducer Response Ratio Plotted as a Function of Frequency on a Three-Cycle Logarithmic Scale $(\mathrm{Hz})$ at $\mathrm{Bi}$ ias Pressures of $7 \mathrm{MPa}$ and $55 \mathrm{MPa}$, for Transducer 537 
Figure 15: Dynamic Sensitivity (\%) Plotted as a Function of Bias Pressure (MPa), for Three Transducers :

Figure 16: Transducer Response Ratio Plotted as a Function of Frequency on a Three-Cycle Logarithmic Scale $(\mathrm{Hz})$ with Working Liquids of Mercury and Silicone $0 \mathrm{il}$, for Transducers 859 and 858 ....... . 50

Figure 17: Dynamic Sensitivity (\%) Plotted as a Function of Bias Pressure (MPa), for Transducers 858 and 857 . . 51 

Development of Dynamic Calibration Methods

for Pogo Pressure Transducers

John S. Hilten, Paul S. Lederer,

Carol F. Vezzetti, and J. Franklin Mayo-Wells

Two dynamic pressure sources are described for the calibration of pogo pressure transducers used to measure oscillatory pressures generated in the propulsion system of the space shuttle. Rotation of a mercuryfilled tube in a vertical plane at frequencies below $5 \mathrm{~Hz}$ generates sinusoidal pressures up to $48 \mathrm{kPa}$, peak-to-peak; vibrating the same mercuryfilled tube sinusoidally in the vertical plane extends the frequency response from $5 \mathrm{~Hz}$ to $100 \mathrm{~Hz}$ at pressures up to $140 \mathrm{kPa}$, peak-to-peak. The sinusoidal pressure fluctuations can be generated by both methods in the presence of high pressures (bias) up to $55 \mathrm{MPa}$.

Calibration procedures are given in detail for the use of both sources. The dynamic performance of selected transducers was evaluated using these procedures; the results of these calibrations are presented. Calibrations made with the two sources near $5 \mathrm{~Hz}$ agree to within $3 \%$ of each other.

Key Words: Bias pressure; calibration; dynamic calibration; dynamic pressure; high pressure; liquid medium; pogo pressure; pressure source; pressure transducer; sinusoidal; space shuttle; transducer.

\section{INTRODUCTION}

This report describes the development of dynamic pressure sources and associated calibration methods for pogo pressure transducers used to measure oscillatory pressures generated in the propulsion system of the space shuttle. These pressure transducers are intended to make measurements over a full-scale range of $140 \mathrm{kPa}$ peak-to-peak in the presence of high static (bias) pressures of up to $55 \mathrm{MPa}$ over a frequency range from I $\mathrm{Hz}$ to $100 \mathrm{~Hz}$.*

A method for transducer calibration was available using a pressure source consisting of a liquid-filled tube mounted on the armature of a vibration exciter [1].** This method was choșen as a starting point for the present work $[2,3,4]$.

$* 1 \mathrm{kPa}=0.145 \mathrm{ps} ; 1 \mathrm{MPa}=145 \mathrm{psi}$.

$* *$ Figures in brackets indicate the literature references, section 8 . 
Whether a given transducer in the shuttle propulsion system is responding to gas pressure, to liquid pressure, or to the pressure of a mixture of phases will depend both on its detailed location in the oxidizer or propellant flow stream and on the flow conditions at any given moment. The use of a liquid-filled tube as opposed to a gas-filled tube does not affect the operating principle of flush-diaphragm-type pressure transducers, although the manner in which differential types respond may be different for gaseous than for liquid media over the frequency range of interest.

\section{EXPERIMENTAL DEVELOPMENT}

\subsection{Background: Discussion of Calibration Using Open-Tube Source}

A considerable amount of work has been carried out on the development of a dynamic pressure source and associated calibration method using a liquid medium for pressure transducers with low full-scale ranges [5]. This hydraulic sinusoidal-pressure source consists of a rigid cylindrical vessel, or tube, closed at the bottom and open at the top, mounted vertically on the table of an electrodynamic vibration exciter. The pressure transducer under test is mounted with its diaphragm in a vertical plane near the bottom of the liquid-filled tube. A vertical orientation of the diaphragm is chosen to minimize the effect of vibration on transducer response. Over that part of the frequency range for which the pressure amplitude is considered to be flat (i.e., frequencies below $20 \%$ of the natural frequency of the filled tube and transducer taken together), the effects of damping need not be considered. With this frequency constraint, the amplitude of the sinusoidal pressure generated within the liquid column and acting on the transducer when the table is driven at a zero-to-peak acceleration of a is given by:

$$
P=a h_{c} \rho
$$

where

$$
\begin{aligned}
\mathrm{P}= & \text { pressure }(P a \text { zero-to-peak) } \\
\mathrm{a}= & \text { zero-to-peak acceleration }\left(g_{\mathrm{n}}\right) * \\
\mathrm{~h}_{\mathrm{C}}= & \text { liquid-column height }(\mathrm{m}) \text { above the center of the transducer } \\
& \text { diaphragm, and } \\
\rho= & \text { density of } 1 \text { iquid }\left(\mathrm{kg} / \mathrm{cm}^{3}\right) .
\end{aligned}
$$

With the exciter table at rest, the static pressure acting on the transducer diaphragm is equal to $h_{c} \rho$, a quantity referred to as "liquid head." Thus, if the tube is vibrated sinusoidally in a vertical direction with a peak acceleration of exactly $1 g_{n}$, the pressure seen by the transducer will vary sinusoidally from a maximum of twice the liquid head to near

*The symbol $g_{n}$ represents the unit of acceleration equal to the standard value of the acceleration of gravity at the earth's surface: $g_{n}=$ $9.81 \mathrm{~m} / \mathrm{s}^{2}$, to three significant figures. 
zero. There is a theoretical limitation on the pressure amplitude generated; an acceleration level sufficiently high to reduce the liquid pressure to zero can never be reached, but only some value near the vapor pressure of the liquid. Operation at higher levels of acceleration will produce wave-shape distortion.

Over the flat range of frequency response, the dynamic pressure source as described serves as a source of calibrated pressure known to within 5\%. The source is an absolute calibration source in the sense that the pressure is calculable from mechanical parameters that can be measured and knowledge of the acceleration imparted to the column. This acceleration, in turn, can be measured with instruments that may be traced through calibration to basic standards.

If the transducer diaphragm is sensitive to vibration, such sensitivity would have the effect of widening any discrepancy between static and dynamic calibrations. Experimental data indicate that correlation between static and dynamic calibrations of a pressure transducer using this source may be expected to be on the order of $\pm 0.1 \%$.

\subsection{Development of Closed-Tube Source}

During the development of the open-tube source, exploratory tests were conducted which indicated that the source could be modified into a closed-tube configuration to accommodate a comparatively high-level bias pressure. This concept served as the basis from which was developed the present vibrating-tube pressure source for calibration of transducers designed to measure small pressure fluctuations in the presence of large static pressures.

A prototype closed-tube column was constructed from an open-tube design. The converted tube is shown in figure 1, left. This tube accommodates two transducers (A) screwed into mounting plates (B). At (C) is the valve which permits the tube to be filled under pressure. The tube is closed at the top by threaded plug (D).

\subsubsection{Pressure Halving in a Closed Tube - During several early} experiments with the closed-tube configuration, it was observed that the output of the pressure transducer mounted on the source was substantially less than the output expected on the basis of $P=a_{c} \rho$. At the same time, the natural frequency of the closed configuration was determined to be approximately double that of the same tube in open configuration. For investigating these results, a closed-tube column $31-\mathrm{cm}$ long was constructed with mounting plates for transducers near the bottom and 6.1 and $11.9 \mathrm{~cm}$ above the bottom (approximately 20 and $40 \%$ of the column length from the bottom, respectively). This tube is shown in figure 1 , right. The results of tests at constant acceleration with the same transducer mounted at the middle and highest level and with the tube both open and closed are shown graphically in figure 2. 
If the transducer is mounted near the bottom end of the tube so that the center of the diaphragm is at a distance, $r$, from the end, the pressure amplitude $P_{O}$ generated in open-tube configuration is given by

$$
P_{0}=a(h-r) \rho
$$

where

$$
h=h_{c}+r=\text { the length of the tube containing liquid, in meters. }
$$

With the same tube closed, the pressure amplitude $P_{C}$ experienced by the transducer will be

$$
P_{C}=a\left(\frac{h}{2}-r\right) \rho
$$

For example, a transducer mounted very close to the bottom end of the tube sees approximately twice the pressure in the open-tube configuration that it sees in the closed configuration; mounted at a point $40 \%$ of the length from the bottom of the tube it sees approximately six times the pressure in the open-tube coníguration that it sees in the closed configuration.

An analysis of these results was conducted and a theoretical explanation developed, reported in detail in [6]. In an open tube, the upper surface of the liquid is unconstrained and therefore becomes the locus of a pressure node. At the lower end of the tube, the velocity of the liquid is constrained to be zero, but acceleration amplitude (and consequently pressure amplitude) is at a maximum value. The result is that pressure amplitude is proportional to distance from the node at the open end. When the tube is closed at both ends, the upper surface of the liquid is also constrained to zero velocity, and pressure maxima of equal amplitude occur at the ends. From symmetry considerations, it can be seen that the pressure node must be located halfway between the ends so that the pressure amplitudes in the liquid column will range from zero at the center to equal maxima, determined by the acceleration amplitude, at the ends. These maxima, resulting from an effective liquid head of one-half of the tube length, are thus one-half of the single maximum for the corresponding open tube. A similar analysis leads to a doubling of resonance frequence of the closed-tube configuration relative to the open configuration.

In summary, a vertical tube completely filled with liquid and closed at both ends behaves like a vertical tube open at the top and of half the height of the closed tube when the tubes are subjected to sinusoidally varying acceleration along their axes.

\subsubsection{Inertial Effects - The analysis given above, predicting} equal pressure amplitudes at both ends of a closed tube, does not take into account effects which tend to deform any real, non-infinitely-stiff tube. Further, the desirability of using a closed-tube column that could be mounted on either a vibration exciter or the windmill apparatus 
(described in 2.3) suggested a tube design in which the transducer would be mounted at the upper end with the result that the tube would be loaded by the mass of transducer and mount.

To investigate the size of the inertial effect, two series of experiments were performed. In the first, a closed-tube column representative of the final experimental transducer-at-the-top design was mounted on the vibration exciter in its intended orientation and then, by means of a special fixture, upside down. The column and fixture are shown in figure 3, with engineering sketches of the column and fixture in figures 4 and 5, respectively. The response of a selected pressure transducer was measured over a range of frequencies and showed a significant, consistent difference between the transducer at top and transducer at bottom. In all cases the response when the transducer was in the bottom position was the larger. On the basis of this experiment, a more detailed experiment was planned. The closed-tube column constructed for these tests is shown in figure 6. Identical transducer-mounting blocks are incorporated into each end of the column, with the filling connection (hidden in the figure) at the mid-plane of the column. A blind, tapped hole at each end of the column permits it to be mounted on the vibration exciter by means of a threaded stud. Loading masses, shown at the left in figure 6 , are attached to whichever end is the free end of the column by means of a machine screw.

In the tests, two similar piezoelectric pressure transducers (identification numbers 535 and 536) were mounted, one on each end of the column. The column was filled with silicone oil at the test pressure of either 7.1 or $55 \mathrm{MPa}$. The filled column was mounted on the exciter table and driven with an acceleration amplitude of $5 \mathrm{gn}$ at $50 \mathrm{~Hz}$. Tests were conducted with first one end of the column up and then the other for loading masses in steps of $100 \mathrm{~g}$ from 0 to $600 \mathrm{~g}$. The outputs of the two transducers were measured and recorded and sensitivities calculated. Figure 7 shows the results, with sensitivities $(\mathrm{mV} / \mathrm{kPa})$ plotted as a function of the added mass $(\mathrm{g})$ and the sum of the added mass and one-half the mass of the column $(\mathrm{g})$. This sum is chosen because the product of the acceleration and this sum represents the compressive force applied to the column, as explained below.

The results of the experiments are qualitatively consistent with excitation of an axial compression mode in the column. The pressure seen by either transducer is the sum of the component generated by volume changes of the column, which are in turn the result of acceleration of the column.

For a column of uniform cross section and wall thickness, and considering only the axial mode, the compressive force will be the product of half the column mass and the acceleration, since the mass is assumed to be distributed uniformly over the length. The change in volume is proportional to the compliances of the column and of the fluid. The contribution of column vibration for frequencies sufficiently far below resonance is in phase with the fluid acceleration component of pressure 
at the column end nearest the exciter table and, consequently, out of phase at the free end. The components will, therefore, add and subtract, respectively, at the two ends. At the midpoint of the column, where the component contributed by column acceleration is zero, only the component contributed by the fluid acceleration is present to a first-order approximation.

Adding additional mass at the free end of the column increases proportionally the compressive forces acting on the column (at twice the rate of an equal change in distributed column mass). Referring to figure 7 , the indication of the transducer at the mounted (bottom) end increases in a linear manner with increasing mass and that of the transducer at the free (upper) end decreases at the same rate with increasing mass, consistent with the analysis. If the readings are extrapolated to lower mass, the two curves intersect at zero mass at a pressure sensitivity corresponding to the pressure component generated by the fluid acceleration alone.

Other vibrational modes such as flexure and radial distension modes, which are much more difficult to analyze, can be suppressed in practice by increasing wall thickness. Increased wall thickness also has the effect of adding mass to the column end, but to a first-order approximation greater thickness does not change the contribution of the distributed mass.

The above analysis requires that a correction factor $C$ for inertial effects be incorporated into the expression for the pressure amplitude in a closed-tube column:

$$
P_{C}=C a\left(\frac{h}{2}-r\right) \rho .
$$

For the column design shown in figure 3, C is determined by measuring and recording transducer output at a convenient constant acceleration amplitude at 11 frequencies $(15,20,25,30,40,50,60,70,80,90$, and $100 \mathrm{~Hz}$ ) with the transducer first at the top and then, with the inverting fixture, at the bottom of the column. The average of the 11 values for each transducer position is calculated. C may then be calculated empirically as

$$
C=\frac{\bar{P}_{\text {top }}+\bar{P}_{\text {bot tom }}}{2 \bar{P}_{\text {top }}}
$$

where

$$
\begin{array}{ll}
\overline{\mathrm{P}}_{\text {top }} & =\begin{array}{l}
\text { average of transducer measurements with transducer in } \\
\text { top position, and }
\end{array} \\
\overline{\mathrm{P}}_{\text {bottom }}=\begin{array}{l}
\text { average of transducer measurements with transducer in } \\
\text { bottom position. }
\end{array}
\end{array}
$$


Note that for the design shown in figure 3, $r=0$ and the expression for pressure amplitude simplifies to

$$
P_{C}=\frac{1}{2} \text { Cahp. }
$$

2.2.3 Column Design and Construction - On the basis of experience with the prototype and other columns, a new closed-tube column was constructed to meet the following design considerations:

1. Material of construction to withstand attack by corrosive liquids and be suitable for use with mercury,

2. Column to be of reduced overall weight to limit loading of vibration exciter or windmill apparatus at low frequencies, especially in 3 to $10 \mathrm{~Hz}$ range,

3. Tube to have increased wall thickness to permit bias pressures of up to $55 \mathrm{MPa}$, and

4. Design to incorporate a minimum number of fluid connections to limit leaks.

In addition, the design was to be simple to machine and suitable for use on the windmill apparatus. The column is shown in figure 3. The tube is type 321 stainless steel, with an outside diameter of $2.54 \mathrm{~cm}$ and a wall thickness of $0.45 \mathrm{~cm}$. A closure is welded into the tube at each end; a blind hole is drilled and tapped into the lower closure for a mounting stud and a through hole is drilled and tapped into the upper closure to mount the pressure transducer. The filling-pressurizing valve is mounted on the side of the tube by means of a short nipple of pipe.

Weight reduction is chiefly achieved in this design by eliminating transducer mounting plates and the relatively massive column end block. One consequence is that the transducer diaphragm is perpendicular to the applied acceleration and hence the transducer response is more likely to be affected than in a right-angle mounting. This disadvantage is more than balanced by the fact that the diaphragm sees a uniform pressure (instead of a pressure gradient) at the end of the tube with $r=0$. The other consequence is that only one transducer may be mounted; however, multiple mounting is used only for development purposes and serves no purpose in the source configuration recommended for use.

2.2.4 Working Fluids - Experience with the open-tube pressure source suggested the use of either silicone oil or mercury as the working fluid. Petroleum oil was also used in a few tests, but showed no advantages over silicone oil and some disadvantages (such as a highly temperature-dependent viscosity); the use of petroleum oil was therefore not pursued. 
For a given liquid-column height and a given vibration-exciter capability, the specific density of the working fluid determines the maximum pressure and amplitude attainable, and the velocity of sound transmission determines the column natural frequency and therefore the maximum useful frequency attainable. Mercury has a high specific density (13.55), a relatively high velocity of sound transmission $(1410 \mathrm{~m} / \mathrm{s})$, and is a hazardous material to handle. The maximum peak-to-peak sinusoidal pressures that can be generated by a closed-tube source with a mercury column height of $36.8 \mathrm{~cm}$ and with a double-amplitude displacement of $1.25 \mathrm{~cm}$ are given in table 1 for various frequencies.

The silicone oil selected for use has a comparatively low specific density (0.97), a moderate velocity of sound transmission $(987 \mathrm{~m} / \mathrm{s})$, and is nontoxic. In addition the silicone oil has good damping characteristics, with a viscosity of $10 \mathrm{St}$ at room temperature. The most significant disadvantage is the low density, which limits the pressure amplitudes available at frequencies below $20 \mathrm{~Hz}$ because of the low accelaration levels produced by the exciter below this limit (see table 1).

\subsubsection{Effect of Variations in Bias Pressure - Small changes in} temperature have been observed to produce large changes in bias pressure. For example, the warmth of an experimenter's hand applied to a closedtube column with zero bias pressure for approximately two minutes resulted in a positive change in bias pressure of $340 \mathrm{kPa}$. A tube also at zero bias pressure cooled slightly below its filling temperature behaved in the erratic manner of a tube with a void. These effects are presumably the result of unequal expansion of fluid and tube and are less severe at high bias pressures than low.

To determine the order of magnitude of the effect of bias-pressure variation on pressure-transducer response, an experiment was conducted with a single transducer (identification number 537) in which the bias pressure was varied from $6.89 \mathrm{MPa}$ to $0.21 \mathrm{MPa}$ in the steps shown in table 2 and the transducer output measured and recorded. The acceleration was held constant at $10 \mathrm{gn}$ peak-to-peak, at $50 \mathrm{~Hz}$. The data in the table indicate the presence of a small, though real, feffect of biaspressure variation on transducer output. However, the maximum deviations from the calculated average of $32.425 \mathrm{mV}$ rms $(+0.175,-0.305 \mathrm{mV} \mathrm{rms})$ are less than $1 \%$ of the average value and thus within the estimated limits of error (see 3.3).

The measured resonance frequency of the source-transducer system is also given in table 2 for each bias pressure, as this measurement for silicone oil provides an indication of bias-pressure changes to within an estimated $170 \mathrm{kPa}$. Resonance frequency determinations are made at an acceleration of $1 \mathrm{gn}$ peak-to-peak, a level chosen to prevent overranging the test transducer. This technique of monitoring bias pressure cannot be used with mercury as the working fluid, because a mercury-filled tube exhibits little change in resonance frequency with change in bias pressure. 
2.2.6 Source Repeatability - Because no apparatus for calibrating transducers for pogo pressure measurements existed prior to the development of the sources described in this report, well-characterized pressure transducers were not available to make measurements of source repeatability. Accordingly, two of the transducers to be calibrated (identification numbers 537 and 859 ) were selected for these measurements. The results are summarized in table 3 , which shows the coefficient of variation of pressure measurements made with the two transducers at various frequencies. No way is available to distinguish the contribution to the observed variations resulting from source fluctuations from that resulting from time-variant changes in transducer performance. However, the source is probably at least as repeatable in performance as the mean of the coefficients of variation for transducer No. 859, on the order of $0.2 \%$.

\subsection{Development of Windmill Source}

The vibration-exciter system used in this work has a displacement capability of $1.3 \mathrm{~cm}$ peak-to-peak and can impart accelerations of $25 \mathrm{gn}$ to an $11-\mathrm{kg}$ mass at frequencies of $30 \mathrm{~Hz}$ and above. With the closedtube column shown in figure 3 , these capabilities do not permit the achievement of sufficient pressure amplitudes over the frequency range of 1 to $3 \mathrm{~Hz}$, which is of particular importance in the pogo application. For example, with mercury as the working fluid, a pressure amplitude of $1 \mathrm{kPa}$ is attainable at $1 \mathrm{~Hz}$ and $5 \mathrm{kPa}$ at $2 \mathrm{~Hz}$. These amplitudes are very much smaller than the $140 \mathrm{kPa}$ desired.

To permit pogo calibrations at low frequencies, a new source was designed to be used in conjunction with the closed-tube vibrating column described in 2.2. The source consists of a closed-tube column which is rotated about one end in a vertical plane in the earth's gravitational field so that the column experiences a sinusoidally varying acceleration of $\pm l g \mathrm{n}$. The configuration gives rise to the name windmill source and is based on earlier work with an earth's field calibrator for accelerometers [7]. The design uses the same physical column used in the vibrating-column source, with the transducer at the outer, or free, end of the tube.

When the tube is rotated at constant angular velocity, the transducer experiences a pressure with two components: a sinusoidally varying component $\left(\triangle \mathrm{P}_{\text {grav }}\right.$ ) produced by the interaction of the rotating mass of fluid and the earth's gravitational field, and a constant component ( $P_{\text {cent }}$ ) resulting from the action of centrifugal force on the mass of the fluid. In addition, the transducer sees any constant bias pressure present.

The force applied to the outer end closure by the mercury is equal to the force required to restrain a mass rotating with the same angular velocity as the mercury, equal to the mass of the mercury, and having the same radial distance to the center of mass as the mercury. Since 
the distribution of mercury per unit length of the tube is uniform, the center of mass is located at $h / 2$ from the center of rotation, and

$$
\begin{aligned}
& F_{\text {cent }}=m \omega^{2} \frac{h}{2} ; \\
& P_{\text {cent }}=\frac{m \omega^{2} h}{2 A}=\frac{\omega^{2} h^{2} \rho}{2}
\end{aligned}
$$

where

$$
\begin{aligned}
& m=\text { mass of mercury }(\mathrm{kg}), \\
& \omega=2 \pi \times \text { rotational frequency }(\mathrm{rad} / \mathrm{s}), \text { and } \\
& A=\text { cross-sectional area of tube }\left(\mathrm{m}^{2}\right) .
\end{aligned}
$$

The maximum pressure is seen by the transducer when it is "down" in the rotational cycle and the minimum when it is "up." Experimental observations show that the difference between these two pressures is

$$
\Delta P_{\text {grav }}=c \frac{a h \rho}{2}
$$

where

$$
\text { a = peak-to-peak acceleration in units of } g_{n} \text {. }
$$

This result is consistent with that obtained from the same closed-tube column on the vibration exciter. While it has not been demonstrated rigorously, the suggestion is made that the time-varying acceleration field seen by the fluid in each configuration is equivalent when the acceleration varies from $+1 g_{n}$ to $-1 g_{n}$, and that the pressures produced in the column on the windmill apparatus are subject to boundary conditions equivalent to those produced on the vibration exciter. To a first approximation, the empirical correction factor $C$ has been taken to be the same as that used before and is defined in the same manner.

The relative magnitudes of $P_{\text {cent }}$ and $\Delta P_{\text {grav }}$ may be compared by means of the following example. Consider a mercury-filled tube 36-cm long and with a cross-sectional area of $1 \mathrm{~cm}^{2}$. The mass of the mercury is approximately $0.5 \mathrm{~kg}$, and at a rotational velocity of 2 revolutions per second (rps), the bias pressure $P_{\text {cent }}$ at the outer end is approximately $140 \mathrm{kPa}$. The effective acceleration is approximately $3 \mathrm{gn}_{\mathrm{n}}$, and the dynamic pressure $\Delta P_{\text {grav }}$ is approximately $48 \mathrm{kPa}$.

An important design goal imposed in the windmill apparatus is that the arm formed by the closed-tube column and the counterbalance rotate smoothly at constant known angular velocity with a minimum of vibration. Also, there should be a minimum amount of energy dissipated in the mainshaft bearings. If these conditions are not met by the apparatus to a sufficient degree, irregularities in rotational motion will result which will in turn produce a distorted pressure waveform. 
Figure 8 shows the apparatus evolved (A), its supporting electronics $(B)$, and the vibration-exciter system (C). A more detailed view of the apparatus is given in figure 9 , with a close-up of the rotating assembly in figure 10 .

Air bearings mounted in blocks (D) support the $3.8-\mathrm{cm}-$ diameter main shaft. The front of the shaft carries a two-piece clamping block (E) into which the windmill arm is mounted. This arm is composed of the closed-tube column (F) and the counterbalance-tube assembly (G) to which it is mounted by a threaded stud. The counterbalance tube has the same outer diameter as that of the column and carries at its free end a weight (H) adjustable in position radially for single-plane static balancing. As noted earlier, the transducer under test ( 1 ) is mounted on the free end of the column. Electrical connection to the transducer is made through slip rings $(\mathrm{J})$ mounted at the rear end of the main shaft. The shaft and variable-speed drive motor (K) are each equipped with toothed pulleys (L); rotational motion is transmitted from the motor to the rotating assembly by means of these pulleys and cog-belt (M). The source of power for the motor is a rack-mounted $d-c$ power supply $(N)$.

Angular velocity is monitored by counting the number of holes in a disk (0) that pass between a lamp and a photoelectric cell in a given interval of time. The disk is fixed to the shaft at a position immediately behind the windmill arm and has 100 equidistantly spaced through holes drilled on a slightly smaller circle than that of the disk itself. A pulse is generated and counted for each hole passage; the resulting count is displayed on a counter $(P)$, which has an adjustable counting interval. A second photocell assembly detects the number of times a single hole in the disk (at a slightiy different radius from the center of the disk than the others) passes between lamp and photocell. This hole, used to provide phase-reference information, is positioned so that it is sensed when the windmill arm is in one of its two horizontal orientations. Photocells and lamps are mounted in block (Q).

The motor drive can be used to produce angular velocities of approximately 0.5 to 5 rps. The upper limit is primarily determined by how well the windmill arm is balanced; however, both limits depend on the degree of smoothness of motor operation at low frequencies. With the drive belt removed, the arm may easily be swung manually up to approximately 2 rps. The low-friction air bearings permit a well-balanced arm to spin freely so that at 1 rps as many as six or seven revolutions may occur with no change in the displayed count of $100 / \mathrm{s}$.

Figure 11 shows the output waveforms from a transducer mounted on the closed-tube column on the windmill apparatus manually spun at $1 \mathrm{~Hz}$ (A) and motor-driven at $5 \mathrm{~Hz}(B)$. The stepped effect of the waveform at $5 \mathrm{~Hz}$ is attributable to the cog-belt drive and to relatively few poles in the motor. For comparison, waveforms are also shown for the same transducer-column combination on the vibration exciter. The waveform at (C) represents $10 \mathrm{~Hz}$ and exhibits some distortion, notably near the peaks. By $25 \mathrm{~Hz}$ (D), little distortion is evident, although close 
examination of the peaks reveals a lack of symmetry. At $100 \mathrm{~Hz}(E)$, no distortion is detectable.

\subsection{Other Source Designs Using Working Liquids}

Because there was no a priori guarantee of success with the closedtube source, several other methods for generating pressures were investigated in parallel until the closed-tube column on vibration exciter and windmill apparatus showed clear superiority with respect to feasibility, simplicity, or the like.

2.4.1 Extensions of the Open-Tube Source - Since the pressure amplitude generated in an open-tube column depends on the acceleration imparted to the column, on the length of the liquid column, and on the density of the liquid, increasing any one or combination of these quantities will result in an increased pressure amplitude. Trade offs -- increasing one quantity at the expense of another -- are also to be considered as long as the ahp product is thereby increased. Restrictions imposed by parameters such as resonance frequency, maximum available exciter displacement at a given load and given frequency, and vapor pressure of the liquid are examples of practical considerations that must also be taken into account.

The use of mercury as contrasted with water or a silicone oil is an example of increasing $\rho$, and no practicable denser fluids are known.

Attempts were made to construct sources with open-tube columns by manipulating the other two parameters: a column for use on the vibration exciter with a liquid height of $137 \mathrm{~cm}, 4.5$ times that of the usual column, and a similar long column mechanically driven through large displacements. In the experiments with the vibration exciter, water was used as the working liquid for convenience, and the column was driven over the range of frequencies from 5 to approximately $20 \mathrm{~Hz}$. A piezoresistive pressure transducer was mounted with the center of its diaphragm one diaphragm radius from the bottom of the tube. Below $5 \mathrm{~Hz}$, the output waveform of this transducer became grossly distorted. Above $20 \mathrm{~Hz}$, the effect of the low resonance frequency of approximately $240 \mathrm{~Hz}$ limited useful response:

Because of the very limited range of frequencies over which the pressure amplitude of the long column is flat to a useful degree (for example, limits of $\pm 5 \%$ of the pressure amplitude are often used to define "flat"), no further work is contemplated or recommended with a long column on the vibration exciter.

Experiments were also conducted in which a vertical long column was driven up and down through various displacements by. means of an eccentric and connecting rod. This mechanical drive was intended to extend the displacement range considerably over that provided by the exciter, with the adjustable eccentric mounted on the drive motor providing peak-to-peak 
displacements of 5.1 to $11.4 \mathrm{~cm}$ in approximately $1.3-\mathrm{cm}$ steps. When the column was set into motion, the signal from a pressure transducer mounted near the bottom of the tube proved to be sufficiently noisy to mask the sinusoidal pressure signal desired, in spite of the fact that considerable attention had been paid to the selection and installation of bearings in which the connecting rod and column were supported. With the drive disconnected, the tube was manually displaced, and a cleaner signal from the transducer was observed.

Analysis indicated that a considerable refinement of the mechanical drive would be required to reduce the noise level, even with a shorter column. The long column is subject to a similar upper-frequency limit imposed by the natural frequency to that of the column described above. For these reasons, no further work is contemplated on mechanical drive systems.

\subsubsection{Other Source Schemes - Two other schemes were investigated} for producing pressures suitable for calibrating pogo transducers. One of these was the use of a closed-tube column on a dual centrifuge which was available for experiment [8]. On the basis of the preliminary work, it was determined that the presence of electrical noise, especially at frequencies on the order of a few hertz, militates against using this form of dynamic pressure source, as does the somewhat exotic nature of the dual centrifuge itself. The other scheme was to use a double-acting piston in a closed-tube column mounted on a vibration exciter. An embodiment of this source was constructed, and limited tests carried out. Despite redesign of the apparatus to reduce the effects of a number of mechanical problems which tended to degrade the pressure waveform, no satisfactory waveform was obtained.

\section{CALIBRATION}

\subsection{Filling the Column}

Experience has shown that filling and pressurizing the closed-tube column so that the working liquid occupies all the available space without any inclusions of gas (air) or other liquids is vital to proper operation of the source. The presence of even small voids alters the behavior of the closed-tube source in the direction of an open-tube source in an unpredictable manner.

3.1.1 Filling Procedure - A schematic elevation of the system used to $\mathrm{fill}$ the column with both silicone oil and mercury is shown in figure 12. Initially the column is not connected to the filling system. A valve-position chart, indicating the sequence of valve operations after the filling system is connected to the column, is also given. To prepare the system for use, the following procedure should be followed: 
1. Close valves $A, B, C$, and $D$.

2. Remove the cap from the liquid reservoir and pour liquid into the reservoir. Pour enough liquid into the reservoir to fill the connecting tubes of the system and the column itself, with a substantial reserve.

Note - A trial run with water may be used to determine the volume of liquid required to fill the system. Be sure the system is dry before filling it with the working liquid.

3. To catch the liquid released in step 5, place a suitable vessel under the free end of the tubing which will later be attached to valve $E$.

4. Open Valve C.

5. Momentarily open valve B; then close it.

Note - The purpose of this step is to purge air from the short connection between the liquid reservoir and valve $B$. As a result of manipulating valve $B$, a small quantity of liquid will fall into the vessel. If the liquid has a density near that of water, some of it will be discharged into house vacuum; if the liquid is mercury, the entire slug of liquid will land in the vessel.

6. Clean the closed-tube column with a suitable solvent to remove grease and other contaminants; then dry. Install the test transducer.

7. Connect the free end of the tubing to $E$. Open valve $E$ if it is not already open.

8. Set the oil piston gage to the required pressure for bias.

9. Follow the sequence of valve operations given in figure 12 .

10. After the last step, "Close Down System," disconnect the tubing from valve $E$.

If the same liquid is to be used the next time a column is to be filled, and if the liquid is not mercury, the filling system may be left as is until that use. At that time, new liquid should be added to the reservoir if required, and the filling operation entered at step 6 . If a different 1 iquid is to be used the next time a column is to be filled, or if the liquid is mercury, the filling system should be emptied and cleaned. 
- A resonance method is used to monitor the adequacy of column filling. The filled column is mounted on the table of the vibration exciter, and the exciter control system set to maintain the acceleration level at $\pm 1 g_{n}$ peak-to-peak. The driving frequency is continuously increased from a few hertz until resonance in the test transducer pressure signal is observed. The resonance peak value should be at least 5 times the level at which the signal is flat to within a few percent over a range of frequencies; for this purpose smaller resonances are to be ignored.* Experience has shown that the resonance frequency measurement for a given column fill should be repeatable to within $25 \mathrm{~Hz}$ of the calculated value.

As reported earlier [4], the piezoelectric type of pressure transducer appears to be the most suitable of those commercially available types evaluated for pogo application. For piezoelectric transducers, the diaphragm is relatively stiff and the increase in volume of the closed-tube column contributed by a piezoelectric transducer when the column is pressurized to as much as $55 \mathrm{MPa}$ is negligible. Thus, for tests on piezoelectric transducers using a given column, liquid, and bias pressure, the resonance frequency range representing satisfactory filling may be determined on the basis of a few carefully performed fillings and corresponding measurements. For a given column, liquid, and bias pressure, a higher measured resonance frequency indicates a more satisfactory filling, with the proviso that it is desirable for the bias pressure to be sufficiently high that bias pressure drift resulting from temperature changes is no more than 1 or $2 \%$.

This proviso is more important for liquids with low bulk moduli (such as 10-St silicone oil or water) than high (such as mercury). For example, the maximum measured drift in a closed experimental tube with a silicone-oil column $29-\mathrm{cm}$ long and pressurized to approximately $65 \mathrm{kPa}$ was over $100 \mathrm{kPa}$ for one 20-min run. The tube was standing free on a bench in the laboratory; although a strain-gage pressure transducer requiring excitation was used (and hence the transducer heated the oil slightly), the transducer had been energized for some 12 hours prior to the test to permit temperatures to stablilize. Ten measurements with piezoelectric quartz-crystal transducer identification number 858 mounted on the closed-tube column showed a variation in resonance frequency from

* Another way of stating this is that the resonance amplitude ratio should be at least 5 . (For the purposes of this report, resonance amplitude ratio is defined as the ratio of the measured maximum amplitude of the pressure transducer signal, at resonance, to the measured amplitude at frequencies below the natural frequency over which the frequencyresponse plot exhibits no significant departure from a straight line parallel to the frequency axis.) With no damping, the resonance and natural frequencies are the same. With the little degree of damping present in the column, these two frequencies are nearly enough the same to permit the substitution of "measured resonance frequency" for "natural frequency" in the definition above. 
1359 to $1598 \mathrm{~Hz}$ with silicone oil bias pressures of 3.5 to $41 \mathrm{MPa}$. Thirty-three measurements with four similiar transducers including identification number 858 over a mercury bias pressure range of 3.5 to $55 \mathrm{MPa}$ showed a variation in measured resonance frequency of 1615 to $1662 \mathrm{~Hz}$. A single transducer with the same type of design (identification number 311). showed resonances of 1717 and $1718 \mathrm{~Hz}$ at $55 \mathrm{MPa}$ in mercury. The detailed data are given in table 4. Figure 13 shows that the shift in resonance frequency with bias pressure is very nearly linear for silicone oil and constant within the estimated measurement error for mercury over the range of bias pressures used. The data points for each plot in some cases represent averages of measurements taken at a given frequency. The silicone data were measured with transducer identification number 858 and the mercury, with 857.

\subsection{Calibration Procedures for Closed-Tube Sources}

The following procedures are those developed as a result of experience with using the two sources to calibrate pressure transducers for pogo measurements. The starting point is that the column has been cleaned, the test transducer installed, and the column filled and pressurized to the desired bias pressure. A general caution relates to the sensitivity of bias pressure to temperature, especially at lower bias pressures for which the percentage change will be greater. Because of this sensitivity, calibrations should be conducted expediently, with no more than $15 \mathrm{~min}$ allowed to elapse between the conclusion of measurements on the vibration exciter and the beginning of measurements on the windmill apparatus. Direct contact between the filled column and any thermal source (including hands) should be avoided. If possible, calibrations should be scheduled for times when the work space in which they are carried out is not subject to large changes in temperature.

\subsubsection{Calibration on Vibration Exciter}

1. Mount the column, transducer up, securely to the exciter table by means of a threaded stud.

2. Connect the output of the transducer to whatever instrument (such as storage oscilloscope, digital voltmeter, etc.) is to be used to measure the electrical pressure signal.

Note - It has been found convenient to make low-frequency measurements up to the neighborhood of $1 \mathrm{~Hz}$ by direct measurement of the trace displayed on the screen of a storage oscilloscope or by measurement of a photograph of the trace displayed on either a storage or non-storage oscilloscope. Above $\mathrm{l} \mathrm{Hz}$, a true-rms digital voltmeter was used, as this was the lower frequency limit of the 
instrument available, and the signal waveform deviated little from a true sine wave. If phase information is desired, it is useful to photograph traces showing both the pressure signal and the signal from the monitor accelerometer of the exciter at selected frequencies over the entire range.

3. Connect other components of the system as required. Energize any equipment requiring a warm-up period.

4. Following the longest specified warm-up period for any item of equipment in use, determine the column resonance frequency as indicated in 3.1.2.

5. If the result of this measurement indicates the column is satisfactorily filled, continue with step 6 . Otherwise, refill the column according to the procedure given in 3.1.1, or according to other accepted procedure. Following refill, begin the calibration procedure again at step 1 of 3.2.1.

6. Set the exciter controller to drive the exciter table at the required acceleration level to generate the desired test pressure. Set the frequency selector to the lowest (test) frequency desired.

Note - The lower frequency limit is determined by the exciter capability.

7. With the exciter energized, measure and record the amplitude of the pressure signal. Record the acceleration level and frequency at which the column was driven. Photograph the signal trace if desired.

8. Set the frequency selector to the next desired test frequency.

9. Repeat steps 7 and 8 until the pressure signal has been measured at all intended test frequencies.

Note - The upper frequency limit should not exceed approximately $20 \%$ of the measured resonance frequency if measurements in only the flat portion of the amplitude-frequency response are desired. To avoid damage to the test transducer, or to the exciter, or to both, do not drive the column near resonance at more than $\pm 1 g_{n}$.

3.2.2 Calibration on Windmill Apparatus - The procedure given below reflects the specific design of the apparatus, for example in detailing the manner in which the air supply to the bearings is varied. This 
information is provided primarily to indicate the kinds of operational aspects that should be considered. The starting point for this calibration is that the amplitude-frequency response for the test transducer has been measured on that portion of the desired frequency range covered by the vibration exciter, and therefore that the column resonance has been measured as a check on filling.

1. Apply air to the air bearings at a pressure approximately one-third more than the manufacturer's recommended running pressure for the calculated load.

Note - For the air bearings used, this higher pressure is $415 \mathrm{kPa}$. The purpose of the higher pressure is to make the bearings stiffer than when running, to prevent damage that might otherwise occur when shock loads are applied to the main shaft, as during mounting of the arm.

2. If the drive belt is in place on the pulleys, remove it from the main-shaft pulley so that the shaft is free to rotate.

3. Assemble the windmill arm by securely mounting the closedtube column to the counterbalance-tube assembly by means of a threaded stud.

4. Install the arm into the two-piece clamping block and lightly tighten the clamping screws.

5. Connect the output of the transducer to the windmill apparatus leads.

Note - It has been found convenient to wind the leads in a loose spiral around the column and secure them with tape, as shown in figure 9.

6. Connect the transducer output from the slip rings to whatever instrument is to be used to measure the electrical pressure signal.

Note - The note under step 2 of 3.2.1 applies, except that phase information for the windmill apparatus is derived from a comparison of the pressure signal to the output of the second photocell, which is recorded as a separate trace.

7. Connect other components of the system as required. Energize any equipment requiring a warm-up period.

8. Balance the arm by moving it back and forth in the clamp until there is little tendency for the arm to rotate from any angular position. Tighten the clamping screws. 
9. Manually spin the arm slowiy and allow it to coast to a stop. (Do not touch the arm directly.) If several such trials indicate a lack of balance by a preferred stopping position, adjust the balance by means of the movable weight on the couterbalance tube.

10. Repeat step 9 until the arm appears to stop at random positions around the circle of rotation.

11. Replace the drive belt on the main-shaft pulley, and on the motor pulley if required.

12. Reduce the air pressure to the air bearings to the recommended running pressure.

Note - For the air bearings used, this pressure is $300 \mathrm{kPa}$.

13. Following the longest specified warm-up period for any item of equipment in use, energize the motor and adjust its controller so that the arm rotates at an angular velocity of approximately 5 rps, as measured by the counter display of the number of holes passing the photocell per selected unit of time.

Note - Not shown in the figures is a wooden box placed around the rotating windmill arm and lined with polyethylene sheeting. This box served as a safety shield to protect both apparatus and personnel and as a means of containment for small amounts of mercury that were occasionally leaked from the column, especially in early experiments at $55 \mathrm{MPa}$. The box also served as a baffle to reduce the amount of air flowing around the tube from the laboratory heating and ventilation system; no attempt was made to seal the windmill arm into the box.

14. Measure and record the amplitude of the pressure signal. Record the angular velocity at which the arm was driven.

15. Readjust the motor controller so that the arm rotates at the next desired angular velocity.

Note - It is useful to start the calibration on the windmill apparatus at $5 \mathrm{~Hz}$ to check the balance, even if a higher frequency is intended to be used. It has been the usual practice with the windmill apparatus to start the calibration with a measurement at $5 \mathrm{~Hz}$ and then to reduce the frequency for each successive measurement. In the region of 
$1 \mathrm{~Hz}$, the drive belt is removed and the arm spun manually for this and lower frequencies.

16. Repeat steps 14 and 15 until a frequency of $1 \mathrm{~Hz}$ is reached.

17. Remove the drive belt from the main-shaft pulley.

Note - The detailed design of the drive system will dictate whether the air-bearing pressure should be raised for this step.

18. Manually spin the arm. When the counter display indicates that the arm is rotating with the desired angular velocity, measure and record the amplitude of the pressure signal. Record the angular velocity.

19. Repeat step 18 until the pressure signal has been measured at all intended test frequencies.

20. Disconnect the column from all instrumentation. Dismount the column from the windmill apparatus.

21. Using suitable precautions, vent the column slowly by opening the value slightly.

22. Remove and clean the test transducer; drain the column.

\subsection{Error Analysis}

The two dynamic pressure sources described in this report combine to provide a capability not before available. There is no "standard pogo transducer" that can be used to evaluate source performance. Repetitive measurements with one or more transducers that experience has shown to be relatively well-behaved provide some measure of source repeatability, as indicated in 2.2.6. It is also possible to calculate transducer dynamic sensitivity at zero bias pressure by other methods and to compare these results with a plot of dynamic sensitivity as a function of bias pressure, the plot data being derived from calibration measurements using the closedtube sources; an example of this type of analysis is given in 4.1 .

Factors contributing to the uncertainty of the pressure available from both sources include (1) uncertainty in the length of the liquid column resulting from machining and measurement inaccuracies; (2) uncertainty in the knowledge of the true density of the working liquid resulting from variations in temperature; (3) uncertainties in the bias pressure resulting from variations in temperature and, to a lesser extent, from the operation of the oil piston gage; (4) uncertainties in the knowledge of the correction factor for inertial effects; (5) uncertainties in various voltage measurements; and (6) electrical noise. To these must be added uncertainty in the acceleration produced by the vibration exciter 
and measured by its accelerometer and the effects of unbalance in the windmill apparatus. In addition, the pressure amplitude in the closedtube column is enhanced as a function of frequency, as is the case with any single-degree-of-freedom system. For example, with a typical column resonance frequency of on the order of $1500 \mathrm{~Hz}$, the pressure amplitude enhancement is $0.1 \%$ at $25 \mathrm{~Hz}$ and $0.5 \%$ at $100 \mathrm{~Hz}$. For dynamic calibrations as a whole, uncertainty in the amount of transducer output resulting from transverse or longitudinal vibrational response, additional voltagemeasurement uncertainties, and additional electrical noise should be added to the uncertainties listed above.

Estimated values for these uncertainties are given in table 5 for two calibration conditions. The overall estimated uncertainty for dynamic calibration measurements using the oscillating source is $\pm 5.8 \%$ (calculated at $25 \mathrm{~Hz}$ ) of the true value and using the windmill source is $\pm 3.7 \%$ (calculated at $2 \mathrm{~Hz}$ ) of the true value. For both estimates, the test transducer was assumed to have an output of $1 \mathrm{~V}$ rms at $\pm 1 g_{n}$; the error resulting from noise will be substantially larger for transducers with significantly lower output.

\section{MEASUREMENTS ON SEVEN POGO PRESSURE TRANSDUCERS}

Calibrations using the two closed-tube sources and other measurements were conducted to characterize the behavior of seven candidate pressure transducers for pogo measurements. The data from some of these measurements also provide information on the calibrations themselves. All transducers evaluated are of the piezoelectric type, with quartzcrystal sensing elements and integral solid-state impedance-conversion circuits. Six of the transducers selected for evaluation were produced by one manufacturer and carry NBS-assigned identification numbers 535 , 536, 537, 857, 858, and 859. The remaining transducer is assigned identification number 311 and is also a commercial product, from a different company. This transducer has a significantly smaller diaphragm and lower specified sensitivity than the others.

For the tests, two transducers were mounted successively in the closed-tube column shown in figure 1, left; all other transducers were mounted on the developed column shown in figure 3. Calibrations over the frequency range 0.2 to $5 \mathrm{~Hz}$ were carried out with the column mounted on the windmill apparatus and over 5 - $100 \mathrm{~Hz}$ with the column mounted on the vibration exciter. The measurement of column resonance frequency, as described in 3.1.2, was used for all tests as a means of detecting the presence of voids.

\subsection{Frequency-Response Measurements}

As an example, plots of response ratio as a function of frequency on a logarithmic scale are shown in figure 14 for transducer 537 at two bias pressures. The working fluid was mercury. Response ratio represents the 
output of the pressure transducer normalized to a reference value equal to the average of the values of transducer output measured at eight frequencies in the range 2 to $25 \mathrm{~Hz}$, including at the end points 2 and $25 \mathrm{~Hz}$. The shape of the curves would be the same if the transducer output as measured in millivolts rms were plotted.

Curves for both bias pressures show a low-frequency roll-off of approximately $3 \mathrm{db}$ at $0.25 \mathrm{~Hz}$. The calibration agreement between the two sources at the juncture point of $5 \mathrm{~Hz}$ is within $0.2 \%$ of the reference value for the calibration at $55 \mathrm{MPa}$, and within $2.8 \%$ for the calibration at $7 \mathrm{MPa}$.

Examination of the plot shown in figure 15 of dynamic sensitivity as a function of bias pressure for transducer. 537 (plots are also shown for 535 and 536) shows that a change of nearly $4 \%$ of the reference sensitivity measured at a bias-pressure level of $55 \mathrm{MPa}$ occurs with a bias pressure change from 7 to $14 \mathrm{MPa}$. Sensitivity is a calculated value (transducer output per unit pressure) based on calibration measurements and is expressed in figure 15 as a percentage of the reference value. This observed change in sensitivity may be responsible for at least some of the difference between calibrations made with the rotating source and the oscillating source at $5 \mathrm{~Hz}$. Calibration runs with the windmill source probably tend to cool the column below ambient because of the motion of the column through the expanding air discharged from the air bearings. Cooling the column reduces the bias pressure. In contrast, there appears to be a slight tendency for the column on the vibration exciter to be warmed with respect to ambient, even though the exciter-table temperature is thermostatically controlled. The differences. shown in figure 14, then, are probably functions of the calibrations and not primarily of the transducer under test, although a transducer property may give rise to them.

The means for varying the bias pressure for the measurements of figure 15 are of interest. An L-shaped length of rigid tubing is mounted to the column valve with the long arm of the $L$ extending upwards parallel to the (filled) column. The column with tube is then placed in a bell jar and the tube filled with the same working liquid as the column, using the procedure given in [5] for filling an open-tube column. The column is mounted on the exciter table and an oil piston gage connected to the open end of the L-tube by means of a short length of flexible tubing and a three-way valve, which is used for bleeding the oil from the piston gage to eliminate air. The purpose of the L-tube is to prevent oil from the piston gage from contaminating the working fluid and to minimize the possibility of air bubbles' being introduced into the column. Following bleeding, the piston gage is set at the bias pressure of the column and the column valve opened. The piston gage may then be reset to the new desired bias pressure; after approximately $5 \mathrm{~min}$, the column valve is closed. It is desirable to remove the $L$-tube before the exciter is energized, but calibrations have been made with the connections all in place at small exciter displacements and with movement of the connecting tubing restrained or damped. Calibrations were made at frequencies of 20,25 , 30,40 , and $50 \mathrm{~Hz}$ and at an acceleration level of $\pm 2.5 g_{n}$. The bias 
pressure was usually changed in increments of $7 \mathrm{MPa}$ and occasionally returned to a previous level as a check.

Further examples of response ratio-vs-frequency, or frequency response, are given in figure 16 for transducers 858 and 859 at a bias pressure of $41 \mathrm{MPa}$. The working fluid used was mercury throughout for transducer 859 and for calibration over the low-frequency range up to $20 \mathrm{~Hz}$ for 858 . At $20 \mathrm{~Hz}$ and above, calibration for 858 was conducted with both silicone oil and mercury. (The low frequency limit for silicone oil is imposed by the combination of the acceleration capability of the exciter and the static head provided by the oil; the calibration was carried out at $\pm 10 \mathrm{gn}$ with oil and $\pm 2.5 g_{\mathrm{n}}$ with mercury.) The agreement between calibration with oil and with mercury is on the order of $2 \%$ of the reference output value.

Plots of dynamic sensitivity as a function of bias pressure are given in figure 17 for transducers 857 and 858 with the data originating from three types of calibration: (1) at zero bias pressure with the NBS quick-opening-valve pressure source, with a rise time of approximately $1 \mathrm{~ms}$ [9]; (2) calibration perforce at zero bias pressure with the opentube source; and (3) calibration at selected bias pressures from 3.5 to $41 \mathrm{MPa}$, inclusive, with the oscillating closed-tube source. Sensitivity is expressed as percent of the reference sensitivity measured at $41 \mathrm{MPa}$. For transducer 857, an extrapolated point for calibration with the oscillating closed-tube source at zero bias would fall between 111 and $112 \%$; for 858, between 107 and 108\%. These extrapolated values and the measured values at zero bias therefore agree to within approximately $3 \%$ of the reference sensitivity.

It should be noted that no static calibrations were attempted with the selected test transducers because of the short time constants associated with piezoelectric instruments.

\subsection{Phase-Shift Measurements}

Measurements of the phase shift between the waveform of the driving signal and the waveform of the transducer pressure signal were made to monitor the presence of anomalies. The phase shift of a well-behaved system should be small and monotonic except in the neighborhood of the resonance frequency. Measurements of the phase shift of transducer 537 for a calibration using the windmill source are given as a typical example in table 6 . The phase shift changes in a monotonic manner from $30 \mathrm{deg}$ at $0.5 \mathrm{~Hz}$ to near $0 \mathrm{deg}$ at $5.0 \mathrm{~Hz}$. The phase shift for the same transducer for calibrations using the oscillating source was measured from 10 to $100 \mathrm{~Hz}$ and found to be approximately 0 deg. Experience indicates that the phase-shift measurement can be made within \pm 3 deg of the actual value. 


\subsection{Repeatability Measurements}

As described in 2.2.6 (which see), two transducers were calibrated repetitively at $1,3,5,10,25$, and $100 \mathrm{~Hz}$ and at bias pressures of 41 (transducer 859) and 55 (transducer 537) $\mathrm{MPa}$. For 537, coefficients of variation ranged from 0.03 to $0.14 \%$ (six measurements each) and for 859 , from 0.08 (six measurements) to $0.33 \%$ (seven measurements). The data are given in table 3 .

\subsection{Acceleration Linearity Measurements}

The same two transducers used in 2.2 .6 and 4.3 were also calibrated at two acceleration levels at $10 \mathrm{~Hz}$ and five at $25 \mathrm{~Hz}$ by means of the oscillating source. The bias pressures were again 41 (transducer 859) and 55 (transducer 537) MPa. The data are given in table 7.

\subsection{Vibration Response Measurements}

The transverse (perpendicular to imparted motion) and longitudinal (along direction of imparted motion) vibration response was measured for one transducer from each of the two manufacturers represented. These measurements were made with the transducer mounted in an aluminum block in turn mounted to the table of the vibration exciter. The acceleration levels used equaled or exceeded the estimated levels to be found in the space shuttle and were as follows: (1) peak-to-peak displacement* of $1.3 \mathrm{~cm}(1.3-\mathrm{cm}$ double amplitude), from 5 to $30 \mathrm{~Hz} ; \pm 15 \mathrm{gn}$, from 30 to $900 \mathrm{~Hz}$; and $\pm 70 \mathrm{gn}$, from 900 to $3000 \mathrm{~Hz}$. Transducer 311 showed a maximum response of $39 \mathrm{kPa}$, or approximately $28 \%$ of the $140-\mathrm{kPa}$ measurement range; transducer 537 showed a maximum response of $3 \mathrm{kPa}$, or approximately $2 \%$ of the measurement range. Other data are given in table 8 .

\section{CONCLUSIONS}

Two dynamic sinusoidally varying pressure sources have been described by means of which candidate transducers for pogo measurements may be calibrated. These sources provide $48 \mathrm{kPa}$ peak-to-peak from 0.2 to $5.0 \mathrm{~Hz}$ (windmill source) and up to $140 \mathrm{kPa}$ peak-to-peak from 5.0 to 100 $\mathrm{Hz}$ (oscillating source using vibration exciter) in the presence of a $\mathrm{d}-\mathrm{c}$ bias pressure of up to $55 \mathrm{MPa}$. Overall calibration uncertainties are a function of both frequency and pressure amplitude, but are probably no more than $\pm 6 \%$ and may be on the order of $\pm 4 \%$ for calibrations with the windmill source.

A peak-to-peak displacement is conventionally specified in this frequency range instead of an acceleration level per se, because the acceleration levels are low, while the displacements are large. 
The requirements on the working liquid are such that mercury is the only recommended 1 iquid for calibrations at frequencies of $20 \mathrm{~Hz}$ and below, although mercury's density, toxicity, and surface-tension properties render it a difficult liquid to handle safely. Above $20 \mathrm{~Hz}$, silicone oil is recommended.

Variations in bias pressure with temperature require that care be taken to minimize the amount of thermal energy transferred into or away from a filled column. The lower the bias pressure, the more important this consideration becomes. Handling problems relating to column temperature changes begin to intensify below the neighborhood of $7 \mathrm{MPa}$, although calibrations have been made at as low as $0.21 \mathrm{MPa}$.

\section{RECOMMENDATIONS}

As has been pointed out, no standard transducers exist to serve as references for the calibration measurements. A comparison between the output signals of two transducers exposed simultaneously to as nearly as possible the same pressure amplitudes would provide corroborative data now lacking. The recommendation is therefore made that a new column with ports for two test transducers be constructed and evaluated.

Means for maintaining the filled column temperature at a stable value at least for the $30 \mathrm{~min}$ or so that is required for a calibration using both sources should be investigated. Possibilities include a thermally insulated column and either deliberate heating or cooling of the column.

\section{ACKNOWLEDGMENT}

During the development of the dynamic pressure sources, the design and construction of the mechanical components was the responsibility of Kurt Muhlberg. Useful information concerning the performance of liquidcolumn sources was supplied by Harlan S. Harman of the NASA G. C.

Marshall Space Flight Center. Richard Kraft of the Mathematical Analysis Section, NBS, provided the theoretical verification of the pressurehalving phenomenon observed with the closed-tube source. The authors gratefully acknowledge the contributions of these people. 


\section{REFERENCES}

[1] Hilten, J. S., Lederer, P. S., and Sethian, J. D., A Simple Hydraulic Sinusoidal Pressure Calibrator, NBS Tech. Note 720 (April 1972).

[2] Hilten, J. S., and Lederer, P. S., Space Shuttle Pogo Pressure Measuring System - A Progress Report Covering Period January 15, 1973 to September 15, 1973, NBSIR 74-562 (July 1974).

[3] Hilten, J. S., and Lederer, P. S., Space Shuttle Pogo Pressure Measuring System - A Progress Report Covering Period December 15, 1973 to June 15, 1974, NBSIR 74-604 (December 1974).

[4] Lederer, P. S., and Hilten, J. S., Space Shuttle Pogo Pressure Measuring System - A Progress Report Covering Period September 15, 1973 to December 15, 1973, NBSIR 75-650 (March 1975).

[5] Vezzetti, C. F., Hilten, J.S., Mayo-Wells, J.F., and Lederer, P. S., A New Dynamic Pressure Source for the Calibration of Pressure Transducers, NBS Tech. Note 914 (June 1976).

[6] Kraft, R., Note on a Vibratory Phenomenon Arising in Transducer Calibration, NBS Tech. Note 856 (February 1975).

[7] Hilten, J. S., Accelerometer Calibration with the Earth's Field Dynamic Calibrator, NBS Tech. Note 517 (March 1970).

[8] Smith, R. 0., Willis, E. A., and Hilten, J. S., A Dual Centrifuge for Generating Low-Frequency Sinusoidal Accelerations, J. Res. Nat. Bur. Stand. (U. S.) 66C, No. 4, 357-362 (1962).

[9] Lederer, P. S., Step-Function Pressure Calibrator, U. S. Patent No. $3,034,332$ (May 15, 1962). 


\section{TABLE 1}

Calculated Pressure Capability of a Closed-Tube Liquid-Column Source for Two Working Fluids at a Constant Displacement

Liquid-Coiumn Height: $36.8 \mathrm{~cm}$

Displacement: $1.25 \mathrm{~cm}$ (double amplitude)

\begin{tabular}{|c|c|c|c|c|c|}
\hline \multirow{2}{*}{$\begin{array}{l}\text { Vibration } \\
\text { Frequency } \\
\quad(\mathrm{Hz})\end{array}$} & \multirow{2}{*}{$\begin{array}{c}\text { Acce leration } \\
\left(g_{n}\right)\end{array}$} & \multicolumn{4}{|c|}{ Generated Pressure* } \\
\hline & & $\begin{array}{r}\text { Mer } \\
\text { Workin } \\
(\mathrm{kPa})\end{array}$ & $\begin{array}{l}\text { cury } \\
\text { as } \\
\text { g Fiuid } \\
\text { (psi) }\end{array}$ & $\begin{array}{l}\text { Silicon } \\
\text { Working } \\
(\mathrm{kPa})\end{array}$ & $\begin{array}{l}\text { fil } 0 \text { il } \\
\text { (psi) }\end{array}$ \\
\hline 5 & 0.6 & 31 & 4.5 & 2.2 & 0.32 \\
\hline 6 & 0.9 & 45 & 6.5 & 3.2 & 0.46 \\
\hline 7 & 1.3 & 61 & 8.9 & 4.3 & 0.63 \\
\hline 8 & 1.6 & 80 & 11.6 & 5.7 & 0.82 \\
\hline 9 & 2.1 & 100 & 14.7 & 7.1 & 1.04 \\
\hline 10 & 2.6 & 130 & 18.1 & 9.2 & 1.29 \\
\hline 15 & 5.7 & 280 & 44.7 & 19.9 & 3.17 \\
\hline 20 & 10 & 500 & 73.4 & 35.5 & 5.21 \\
\hline 25 & 16 & 780 & 113 & 55.4 & 8.02 \\
\hline 30 & 23 & 1120 & 163 & 79.5 & 11.6 \\
\hline 40 & 41 & 2000 & 290 & 142 & 20.6 \\
\hline
\end{tabular}

*Pressure values given are peak-to-peak. 
Effect of Bias-Pressure Variation on Transducer Response with Silicone $0 \mathrm{il}$ as the Working Fluid

\section{Acceleration: $10 \mathrm{~g}$ peak-to-peak Acceleration Frequency: $50 \mathrm{~Hz}$ \\ Transducer: No. 537}

Measured

Bias Pressure $(\mathrm{MPa})$

Resonance Frequency

$(\mathrm{Hz})$

6.89

2227

2224

2222

2217

2212

4.14

3.45

2.76

2.07

1.38

0.69

0.21

6.89
2208

2206

2200

2196

2193

2188

2233
Transducer Output

(mV rms)

32.12

32.28

32.38

32.46

32.56

32.60

32.58

32.52

32.50

32.42

32.36

32.32

av 32.425 


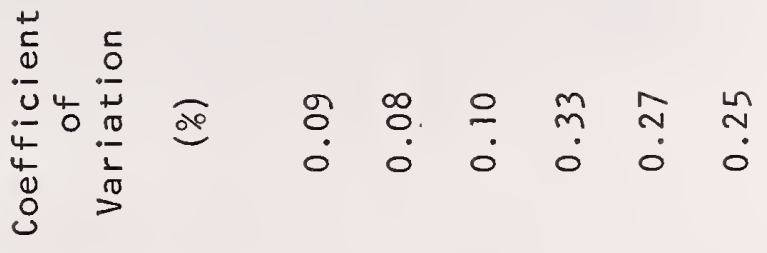

$$
\begin{aligned}
& \text { 业兵 }
\end{aligned}
$$

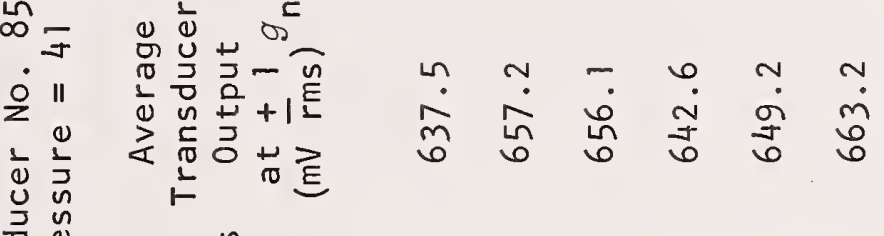

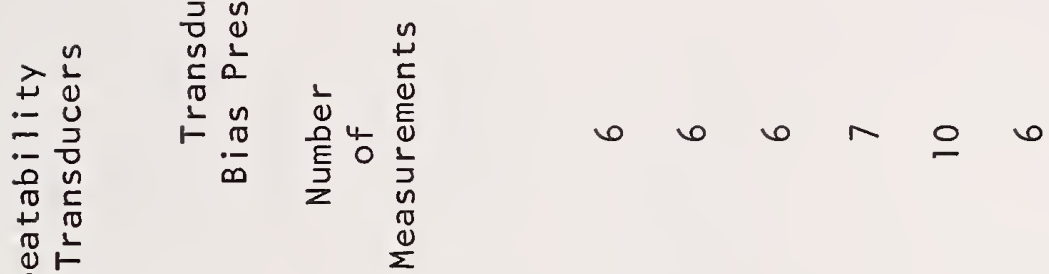

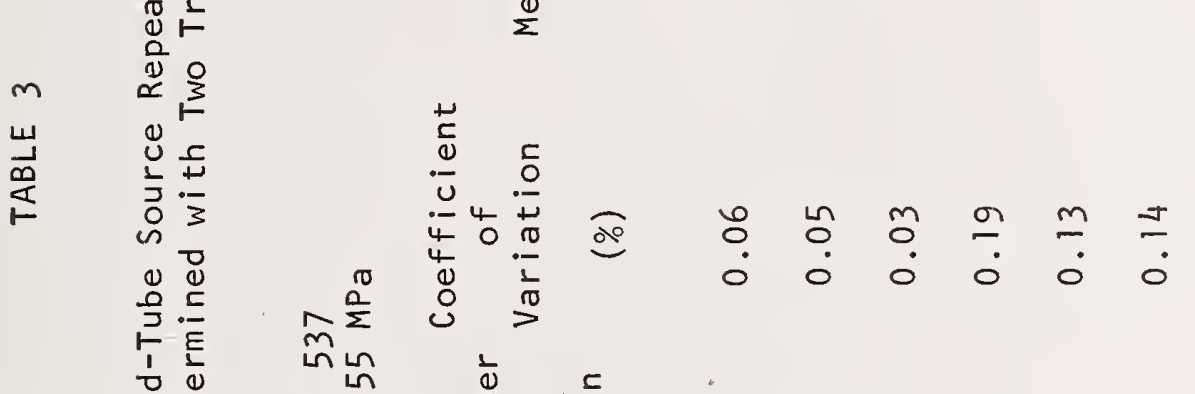

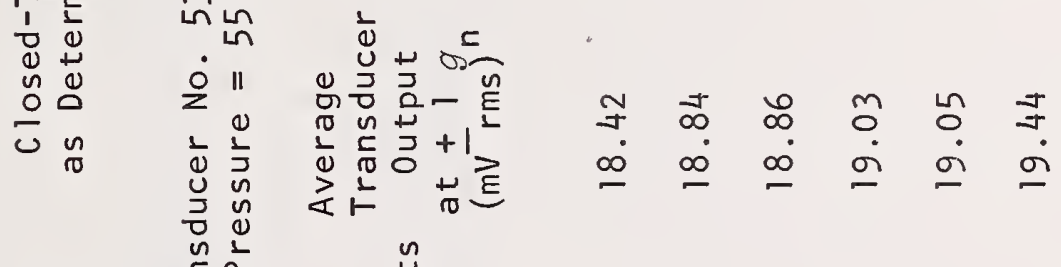

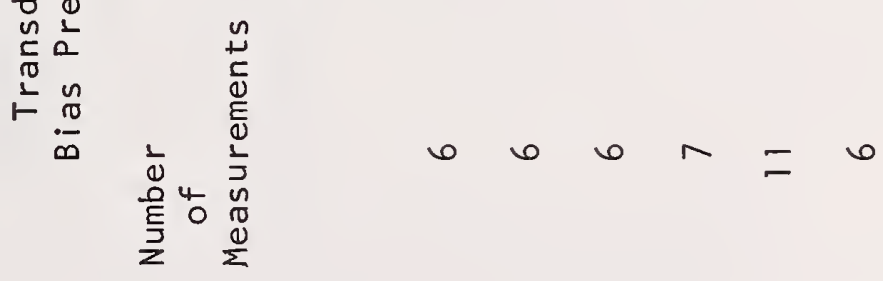

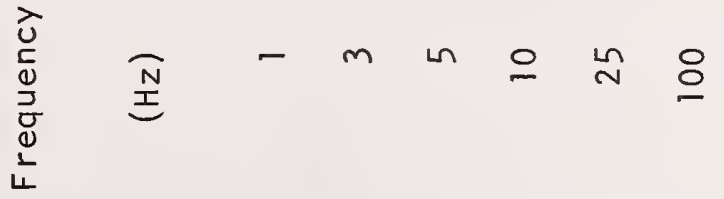


TABLE 4

RESONANCE FREQUENCY AS A FUNCTION OF CLOSED-TUBE COLUMN BIAS PRESSURE FOR MERCURY AND SILICONE OIL

Length of Liquid Column: $36.8 \mathrm{~cm}$

Transducer Identification Number

537

Resonance Frequency

$(\mathrm{Hz})$

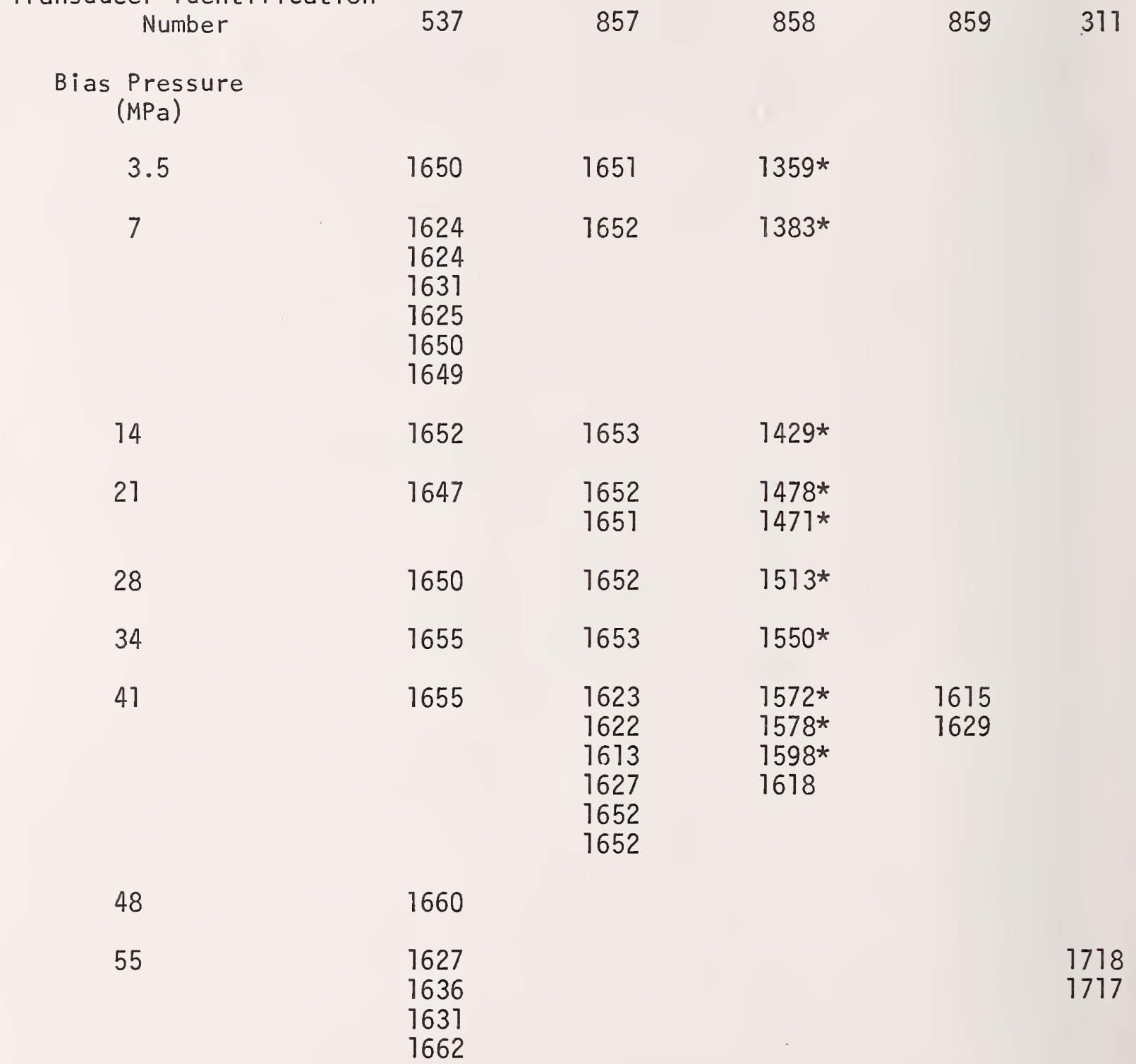

* Denotes use of silicone oil, all other measurements are for mercury. 
TABLE 5

Factors Contributing to Estimated Transducer Calibration Error ${ }^{a}$

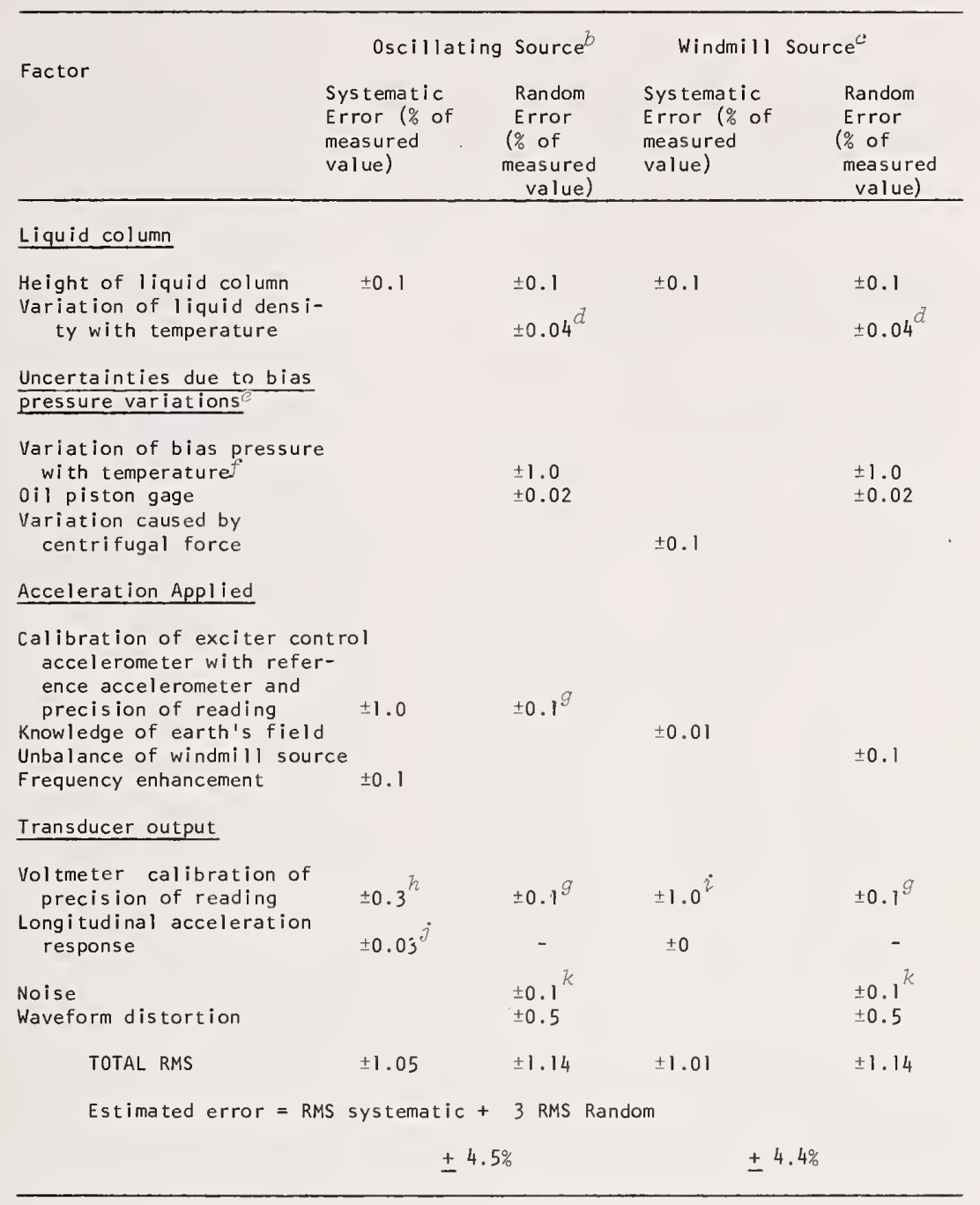

\footnotetext{
For typical calibration using a $36.8-\mathrm{cm}$ column of mercury at a bias pressure of $55 \mathrm{MPa}$.

$b$ at a frequency of $25 \mathrm{~Hz}$.

$c_{\text {at a f }}$ requency of $2 \mathrm{~Hz}$.

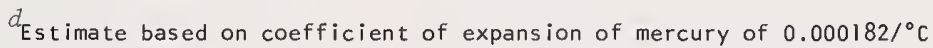
and variation of $\pm 2^{\circ} \mathrm{C}$.

$e^{e}$ The magnitude of the effect of bias pressure variation on transducer output depends on the linearity of the transducer response; values given are for transducer 537.

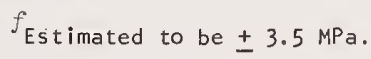

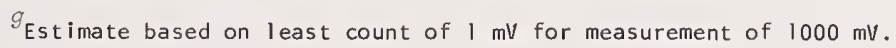

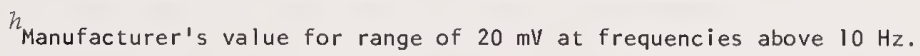

'Manufacturer's value for measurements at frequencies from 1 to $10 \mathrm{~Hz}$.

$j$ Depends on transducer; value given is for transducer 537.

This figure corresponds to $1 \mathrm{mV}$ for a typical calibration.
} 
TABLE 6

PHASE SHIFT BETWEEN PRESSURE AND TRANSDUCER-OUTPUT WAVEFORMS FOR TRANSDUCER 537 ON WINDMILL APPARATUS

\begin{tabular}{|c|c|}
\hline $\begin{array}{l}\text { Frequency } \\
\qquad(\mathrm{Hz})\end{array}$ & $\begin{array}{c}\text { Phase Shift } \\
\text { (deg) }\end{array}$ \\
\hline $\begin{array}{l}0.5 \\
0.8 \\
1.0 \\
1.2 \\
1.5\end{array}$ & $\begin{array}{l}30 \\
19 \\
16 \\
12 \\
10\end{array}$ \\
\hline $\begin{array}{l}1.8 \\
2.0 \\
2.5 \\
3.0 \\
4.0\end{array}$ & $\begin{array}{l}8.0 \\
6.0 \\
5.0 \\
4.5 \\
3.5\end{array}$ \\
\hline 5.0 & $\simeq 0.0$ \\
\hline
\end{tabular}




\section{TABLE 7}

Acceleration Linearity Measurements for Two Transducers

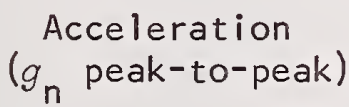

Relative Transducer Output Transducer $859^{a}$ Transducer $537^{b}$ $\left(\mathrm{mV} \mathrm{rms} / g_{\mathrm{n}}\right) \quad\left(\mathrm{mV} \mathrm{rms} / \mathrm{g}_{\mathrm{n}}\right)$
$a t$
$10 \mathrm{H} \mathrm{Z}$

0.5

639.1

19.19

1.0

638.4

18.95

a $t$

$25 \mathrm{~Hz}$

0.5

645.1

19.35

1.0

644.9

19.13

1.5

644.8

19.09

2.0

644.7

19.09

2.5

647.2

19.08

${ }^{a}$ The bias pressure for these measurements with Transducer 859 was $41 \mathrm{MPa}$. ${ }^{b}$ The bias pressure for these measurements with Transducer 537 was $55 \mathrm{MPa}$. 


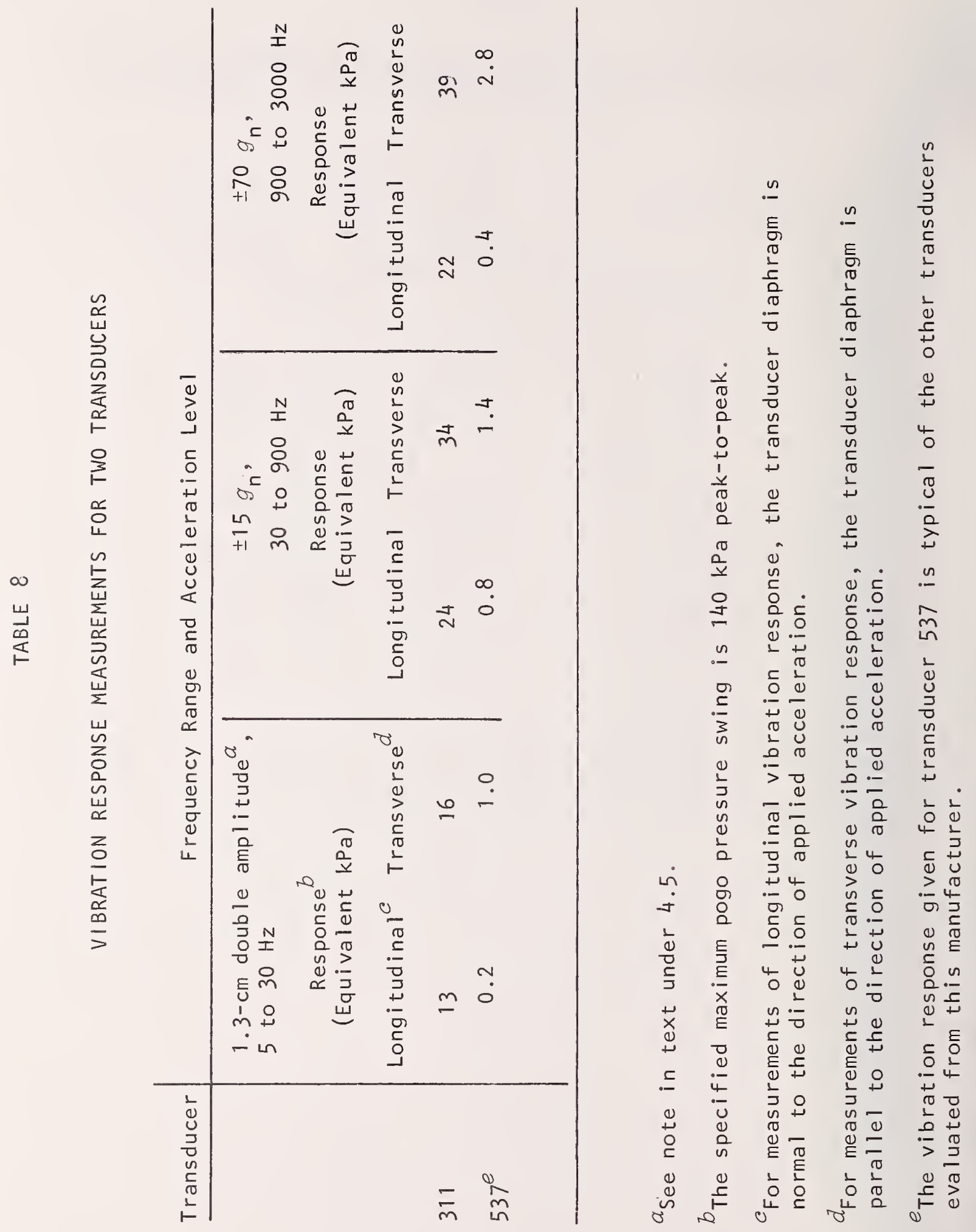



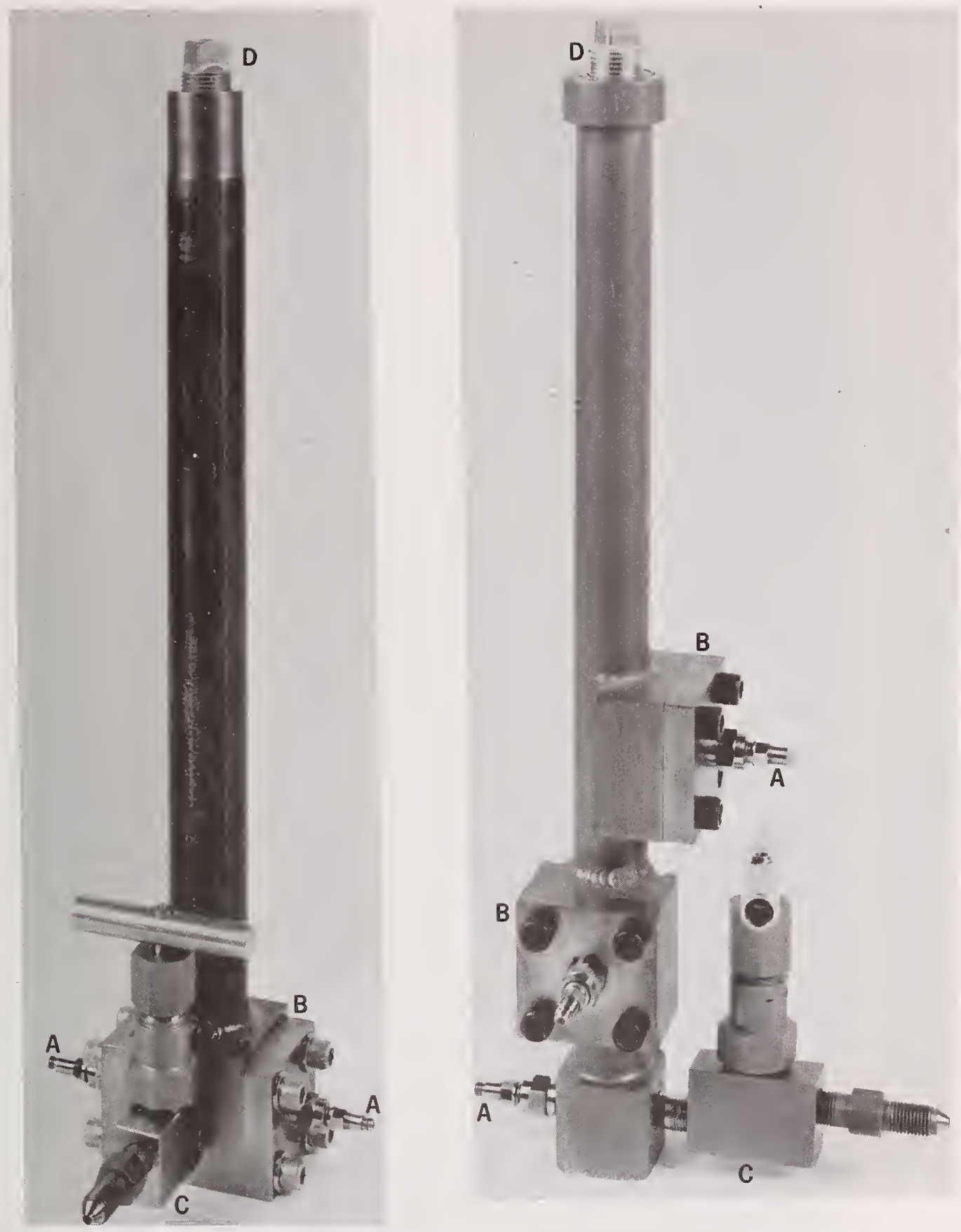

Figure 1. Two source columns used in early experiments. That on the left is a conversion from an open-tube design. The column on the right was constructed to permit source pressure measurements at several heights on the column, as described in the text. Identified are pressure transducers (A), transducer mounting plates (B), column valves for filling and pressurizing $(C)$, and removable plugs (D), used to permit operation in either closed- or open-tube configurations. 

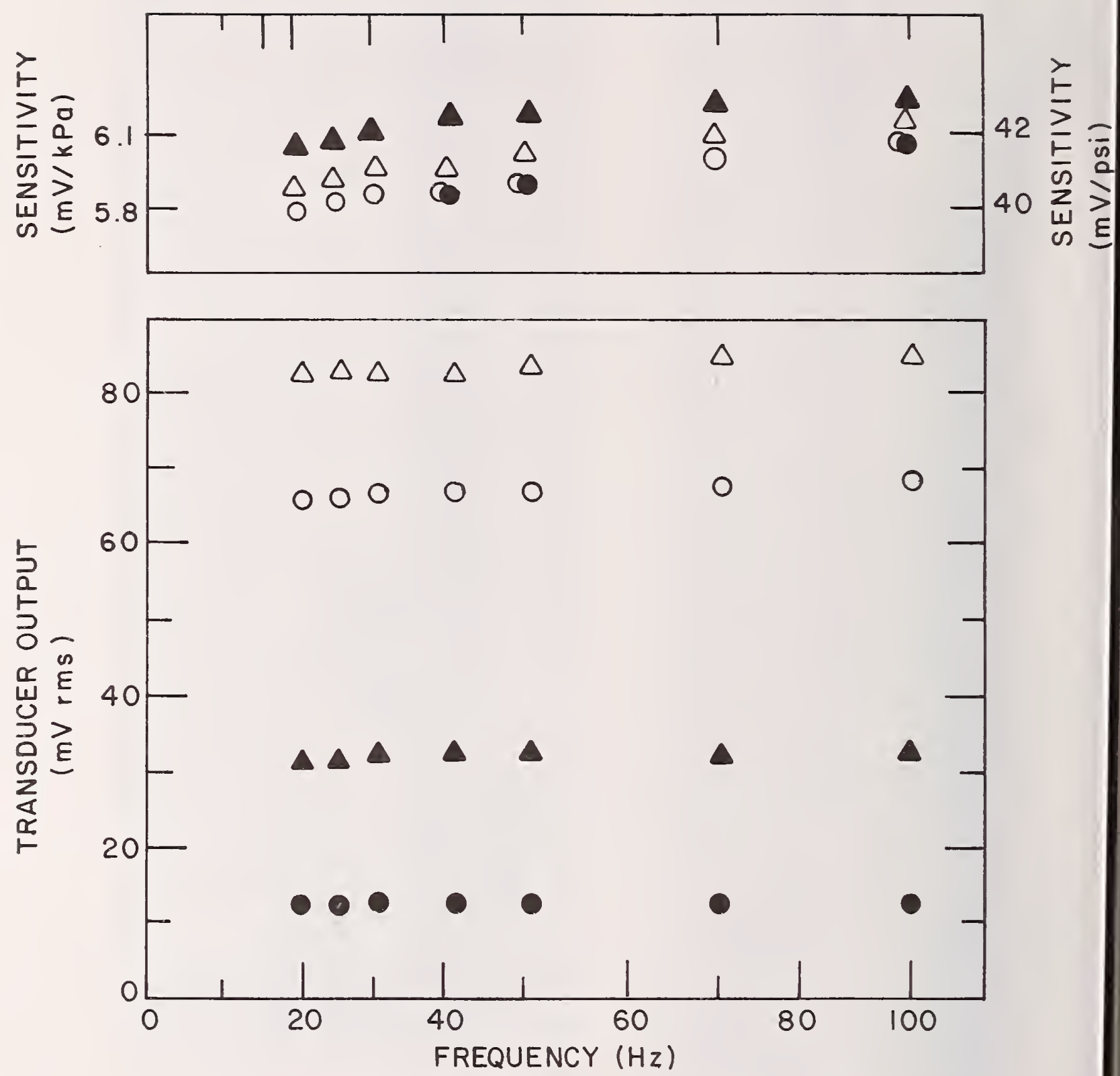

Figure 2. Transducer output (mV rms) at constant acceleration plotted as a function of frequency $(\mathrm{Hz})$ for two transducer locations and for open- and closed-tube configurations. The upper plot shows transducer pressure sensitivity ( $\mathrm{mV} / \mathrm{kPa}$ or $\mathrm{mV} / \mathrm{psi}$ ) as a function of frequency $(\mathrm{Hz})$. Triangles indicate measurements made with the transducer $6.1 \mathrm{~cm}(20 \%)$ from the bottom and circles, $11.9 \mathrm{~cm}(40 \%)$ from the bottom. The open symbols represent open-tube measurements and the filled symbols, closed-tube measurements. 


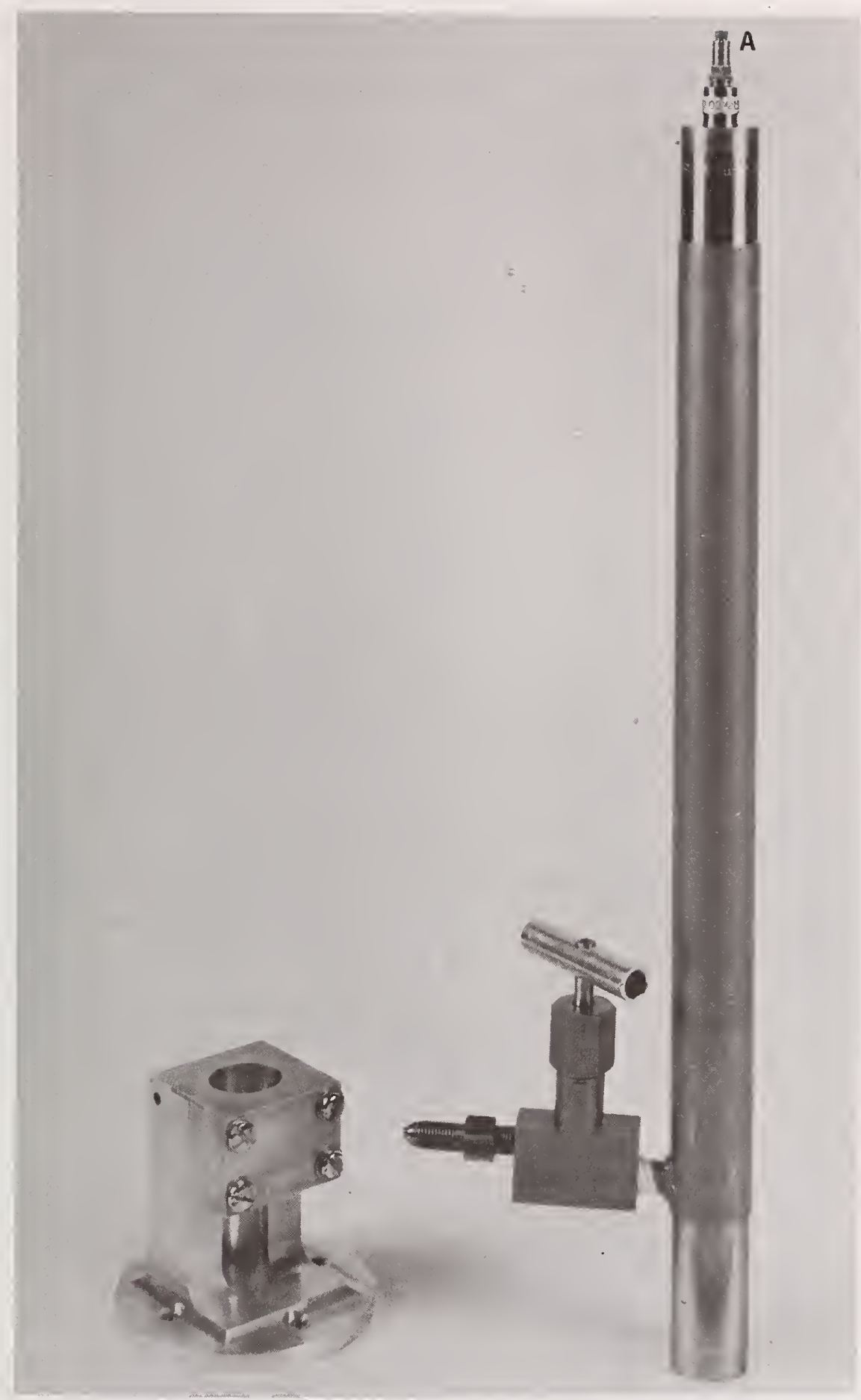

Figure 3. The developed closed-tube column, with the transducer (A) at the top, or free, end. The fixture at the left permits operation with the column inverted. 


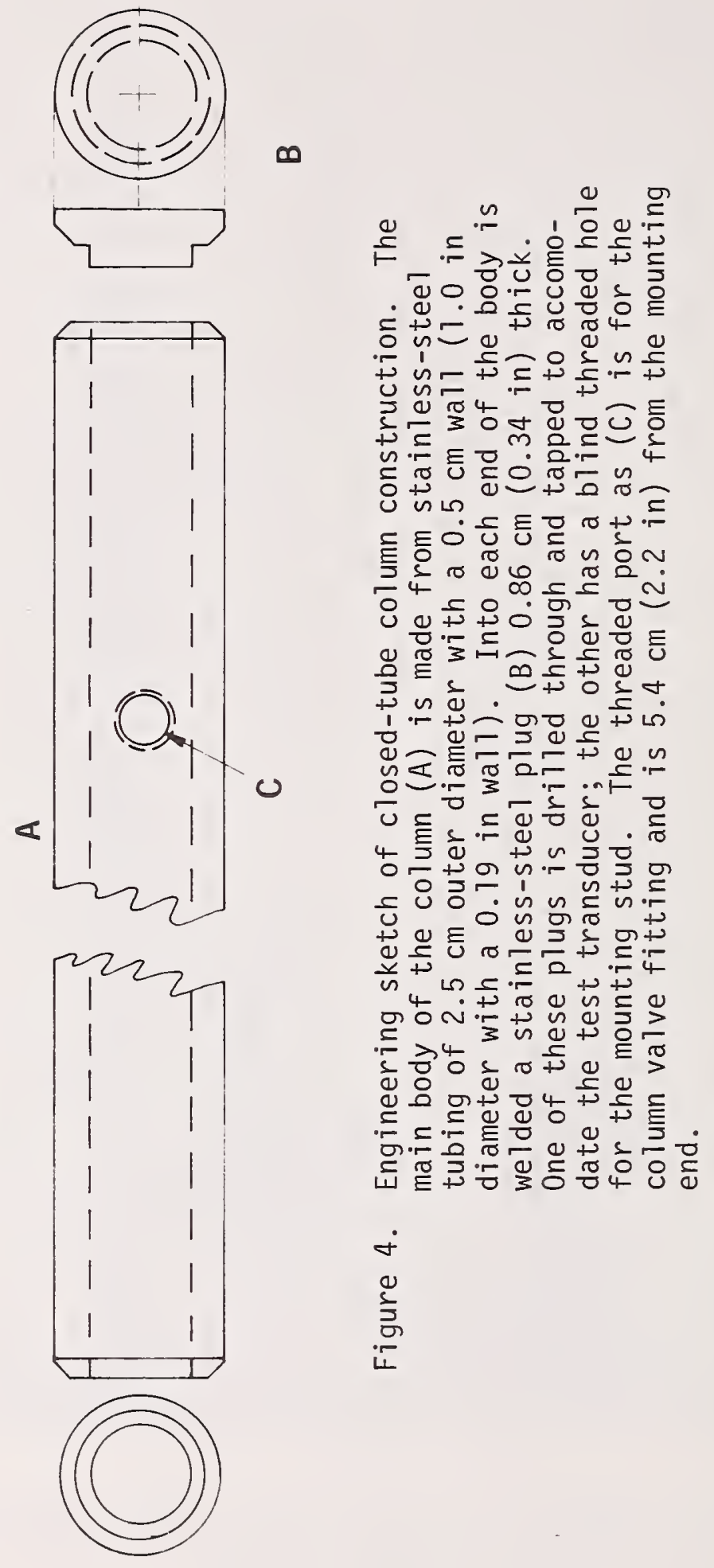



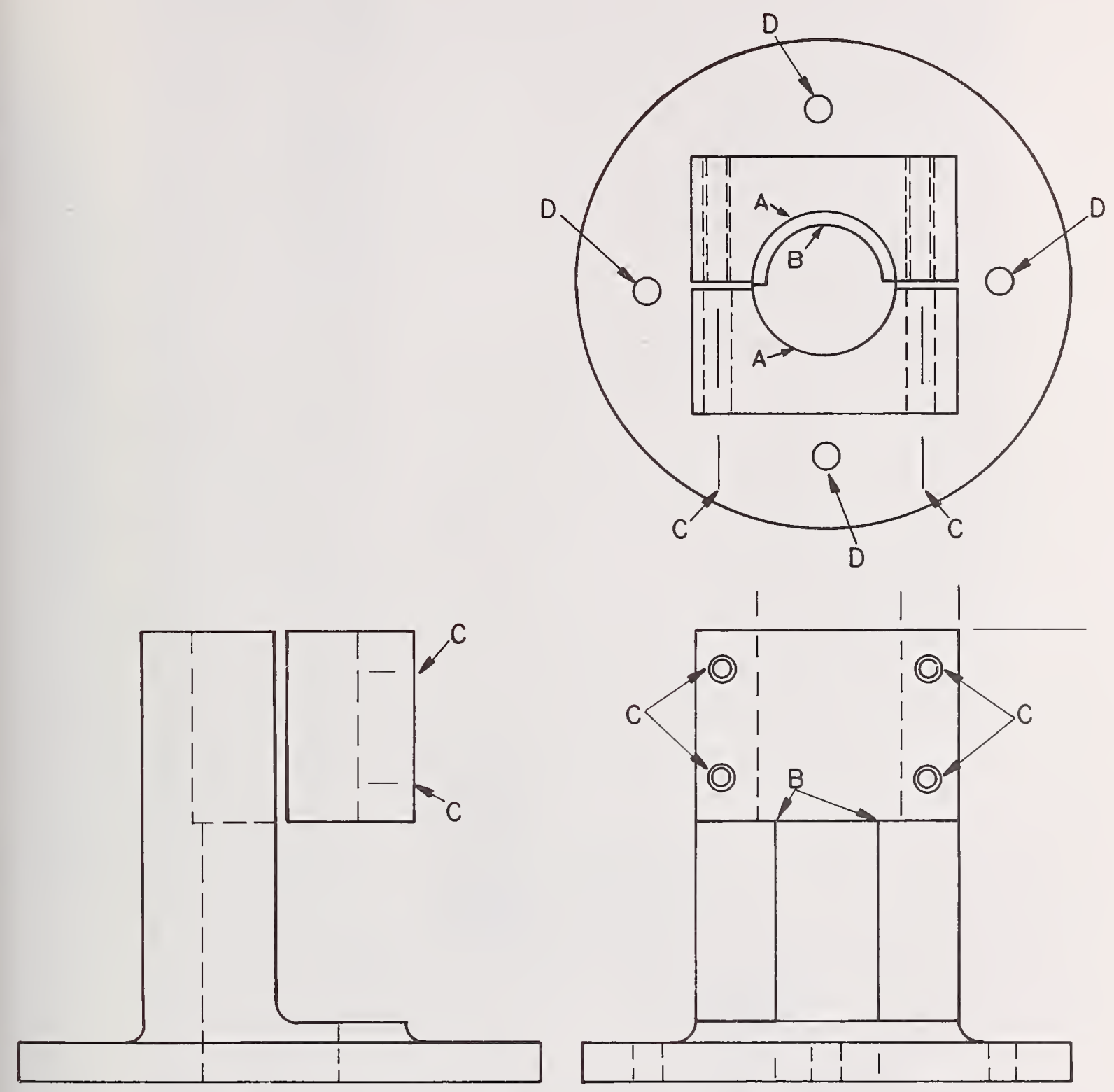

Figure 5. Engineering sketch of two-piece fixture used to mount the column (shown in figure 3 ) inverted. The two clamping surfaces $(A)$ in the cap and main body act on the outside surface of the column, with the effective bore diameter matching the column diameter. The step at (B) limits the depth to which the column is inserted, to provide clearance for the test transducer. Four clamping screws pass through clearance holes $(C)$ in the cap and thread into the main body; the clear holes (D) are for mounting screws. 


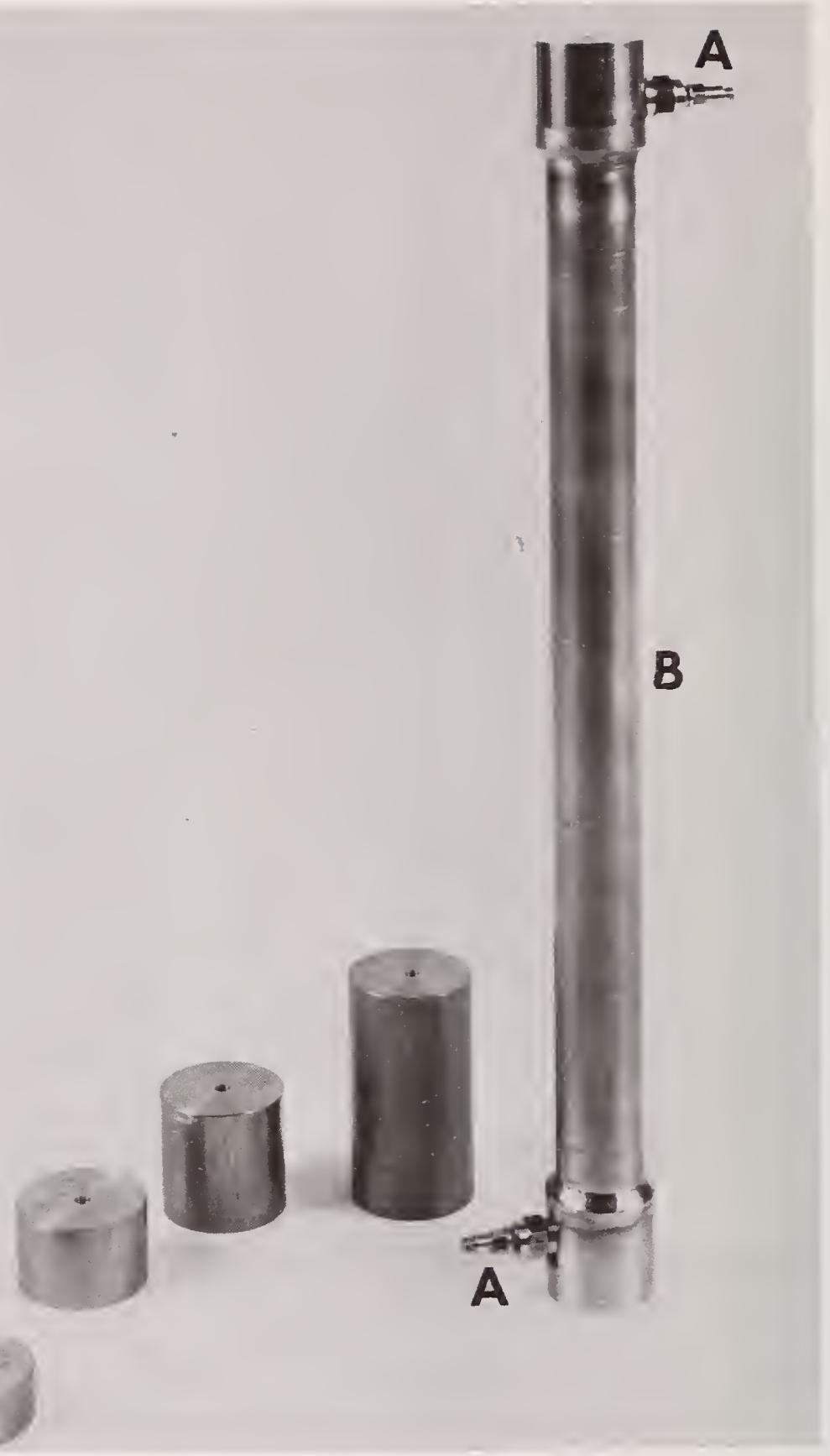

Figure 6. Closed-tube column with provisions for mounting a test transducer (A) at each end for an experimental investigation of inertial effects, as described in the text. The port for the column valve [position indicated by (B)] is on the hidden side of the column; the valve was not mounted when the photograph was taken. The loading masses used in the experiments are shown at the left of the column. 


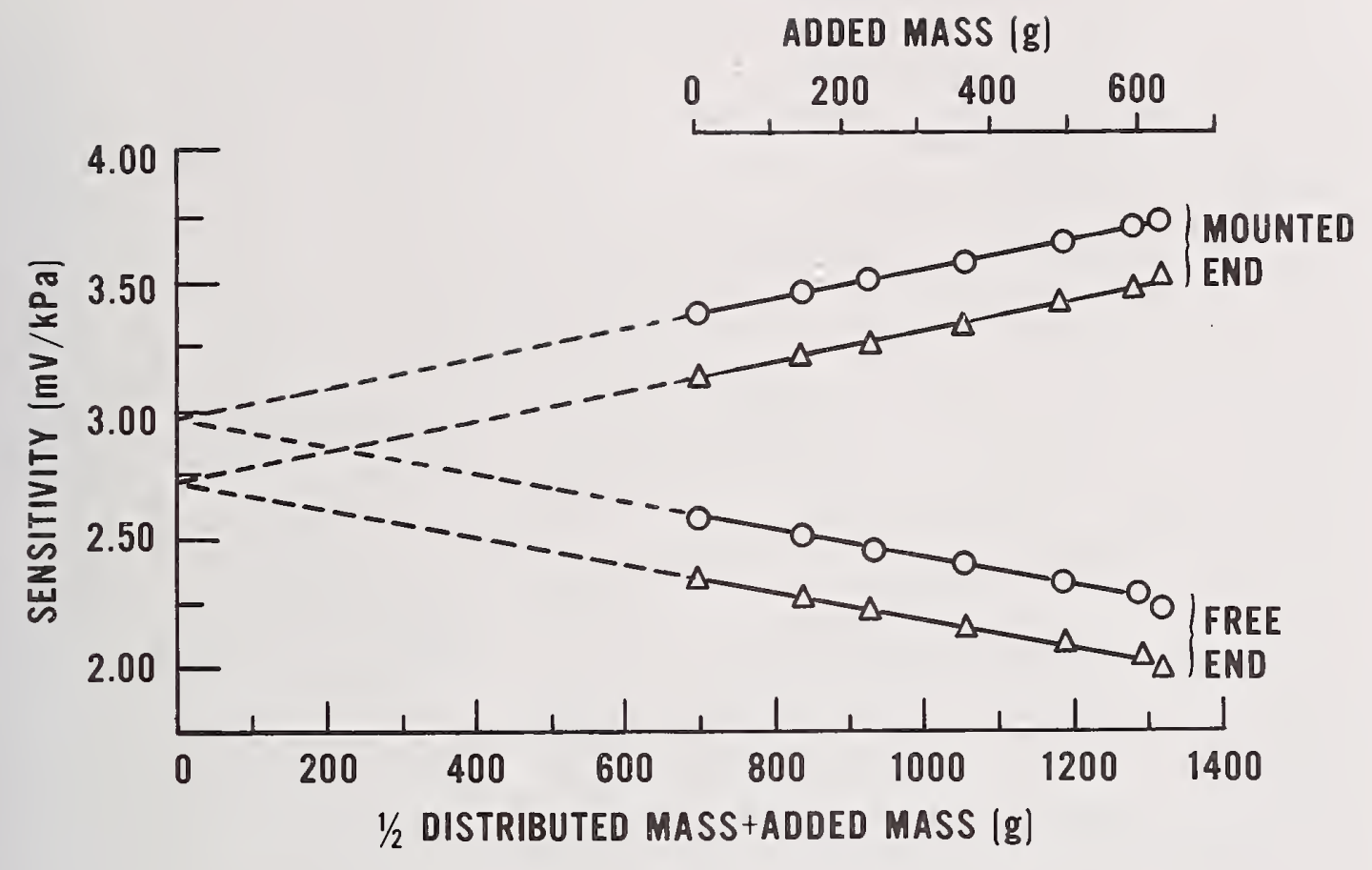

Figure 7. Transducer sensitivity $(\mathrm{mV} / \mathrm{kPa})$ as a function of added mass $(\mathrm{g})$ and of a quantity $(\mathrm{g})$ equal to the sum of the added mass and one-half the distributed mass, the distributed mass being the mass of the column shown in figure 6 . Plots are shown for two transducers mounted in turn at each end of the column. Circles identify measurements taken with transducer number 535; and triangles, with transducer 536. The extrapolated sensitivity at zero mass corresponds to the pressure component generated by the acceleration of the liquid, as described in the text. 


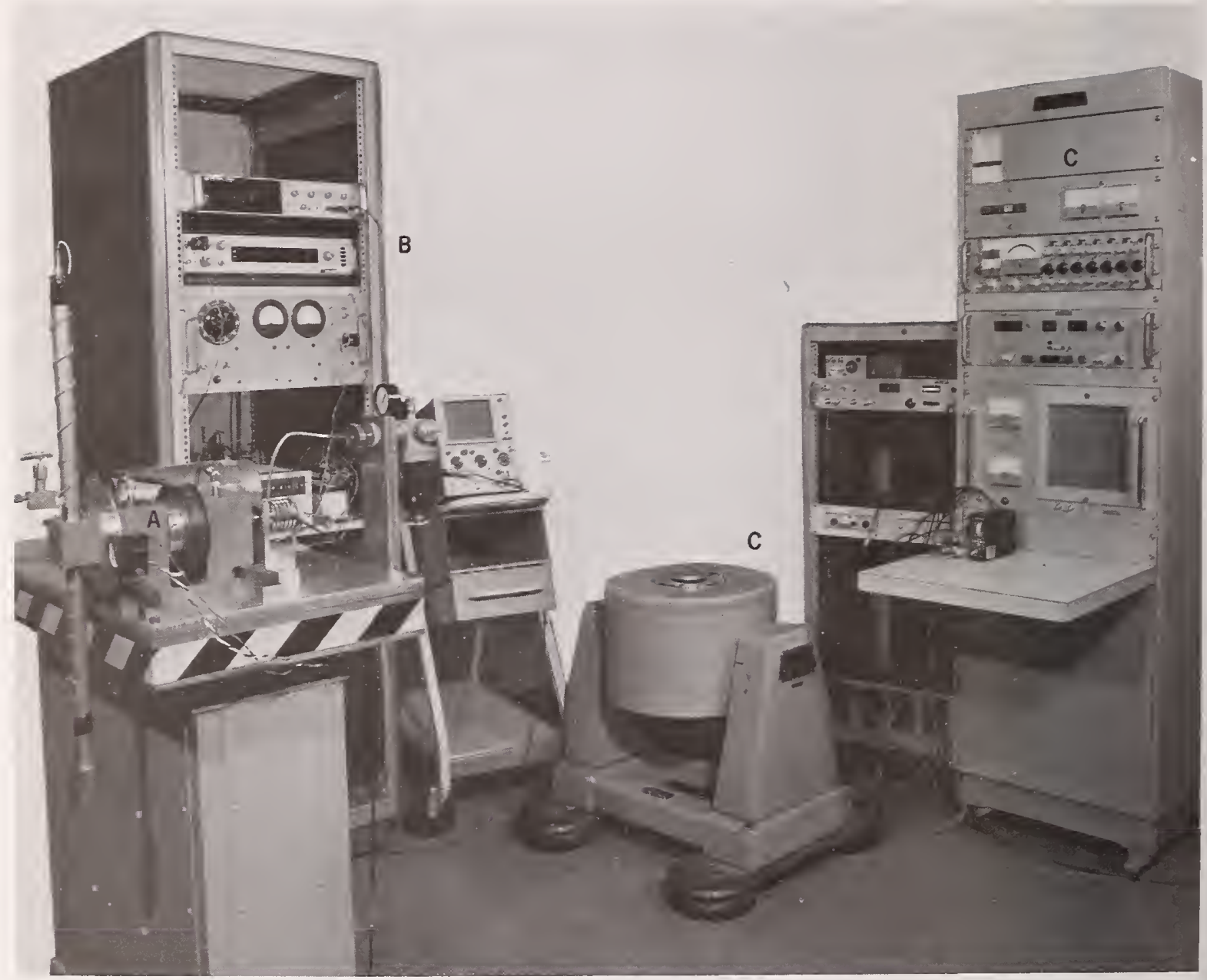

Figure 8. Apparatus used in the calibration of pressure transducers for pogo measurements. The windmill source is shown at (A) with supporting electronics in rack (B). The vibrationexciter system which forms part of the oscillating source is at (C). 


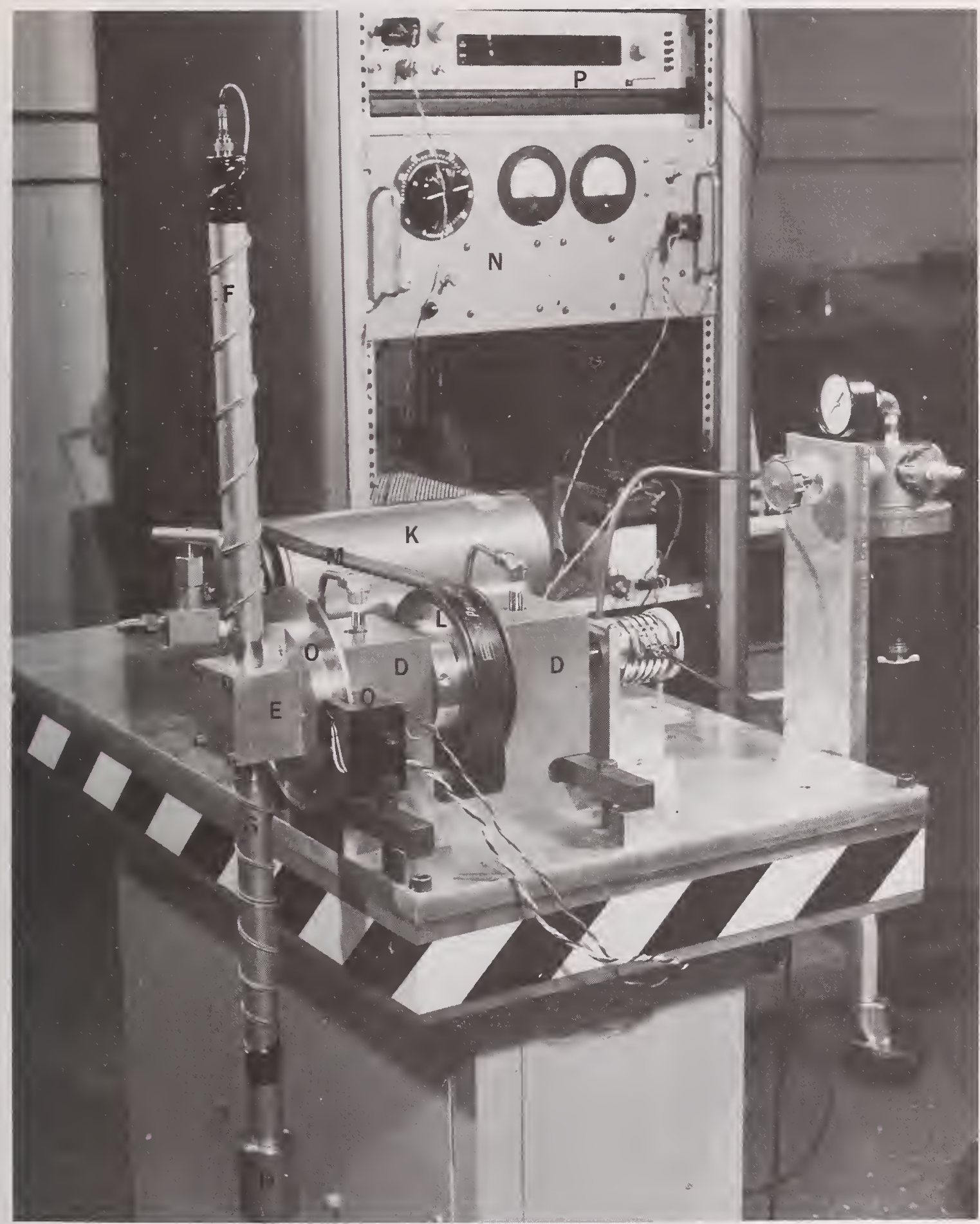

Figure 9. The windmill source, consisting of the closed-tube column mounted on the windmill apparatus. Identifications of the various components are given in the text. 


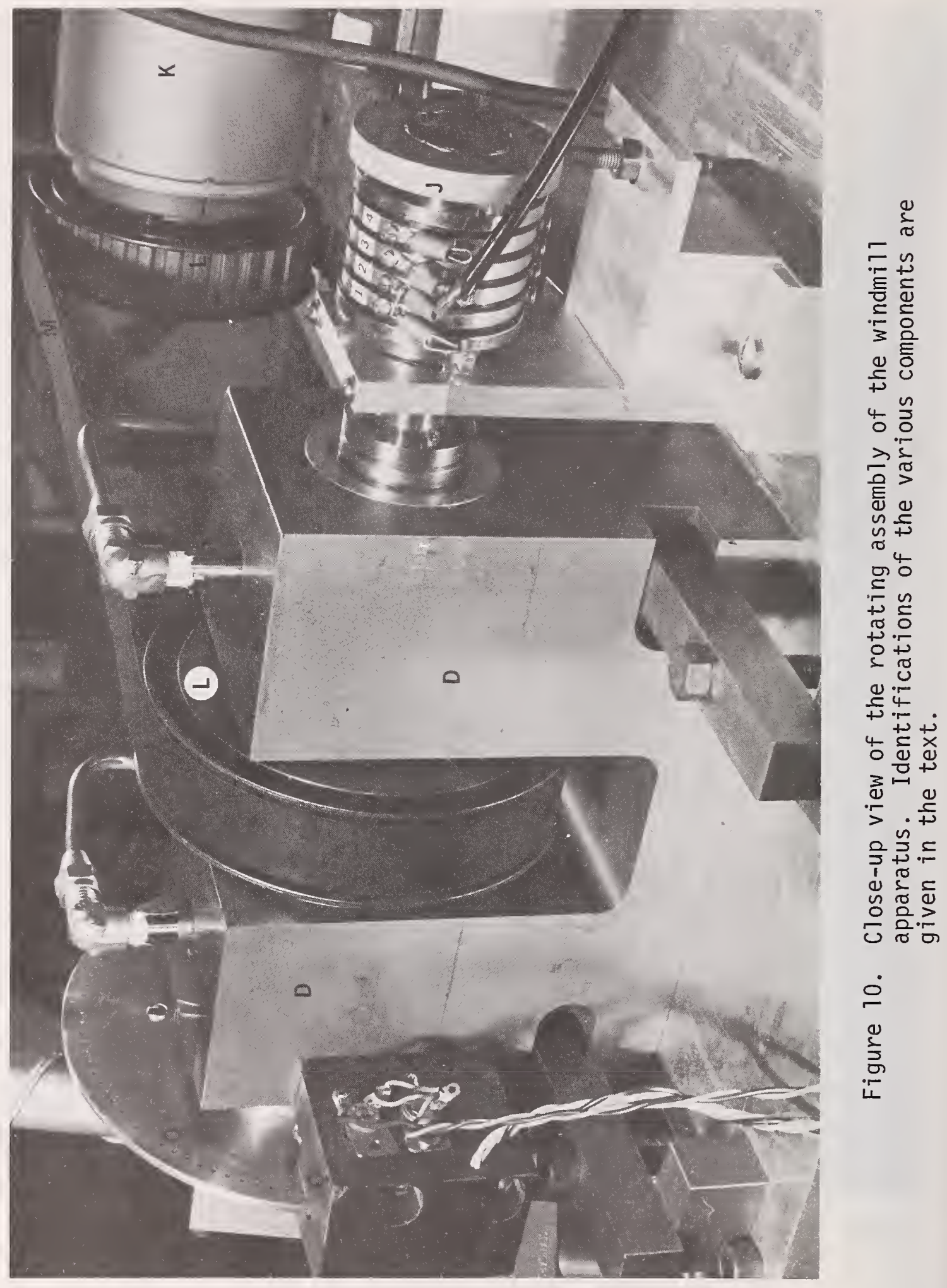




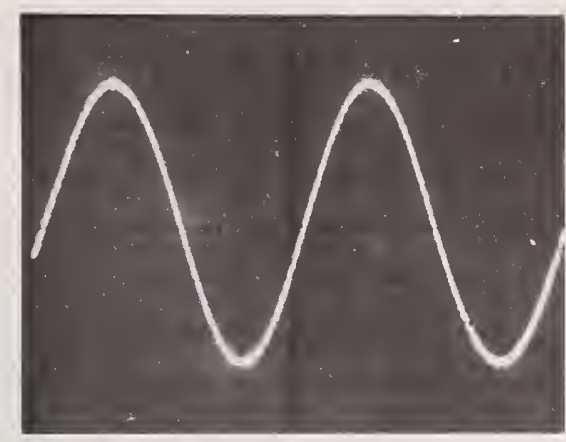

A

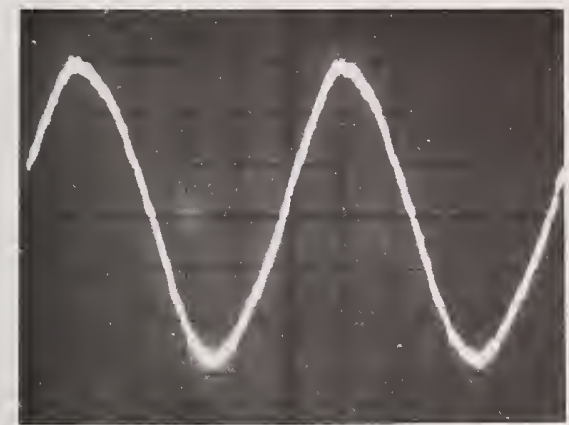

C

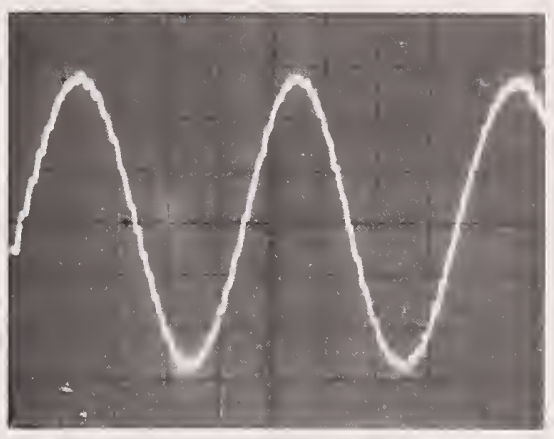

B

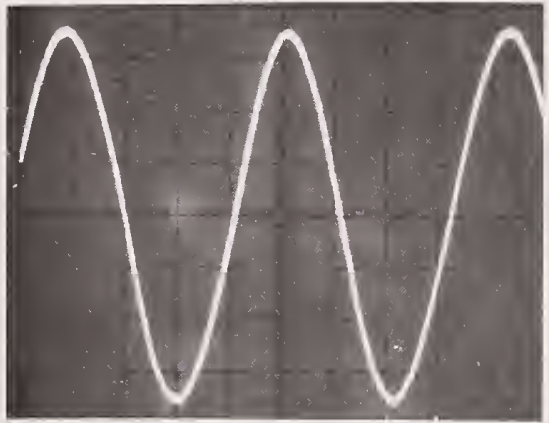

D

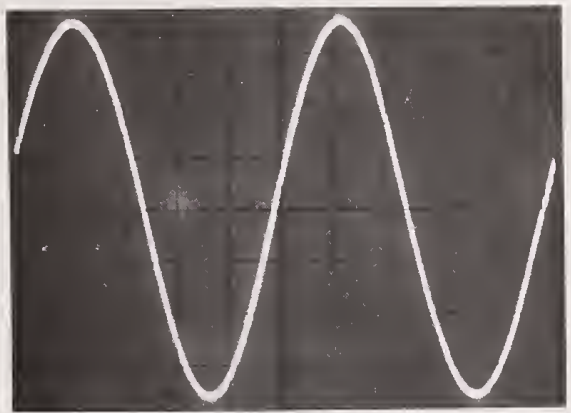

$E$

Figure 11. Photographs of oscilloscope traces of waveforms from a test transducer calibrated on the windmill source $[(A)$ and $(B)]$ and on the oscillating source $[(C),(D)$, and $(E)]$, at several frequencies. Photograph (A) is of a trace taken at $1 \mathrm{~Hz}$ (angular velocity of 1 rps) with the windmill arm manually spun. Photograph (B), of a trace taken at $5 \mathrm{~Hz}$, shows stepping in the waveform attributable to the cog-belt drive and to poles in the drive motor. Distortion in photographed trace $(C)$, taken at $10 \mathrm{~Hz}$, results from deterioration of the acceleration waveform of the vibration exciter at low frequencies, particularly near its displacement limits. At $25 \mathrm{~Hz}$, the acceleration waveform of the exciter has little distortion as revealed in the transducer output waveform, trace photograph (D). At $100 \mathrm{~Hz}$, no distortion is detectable, trace photograph (E). 


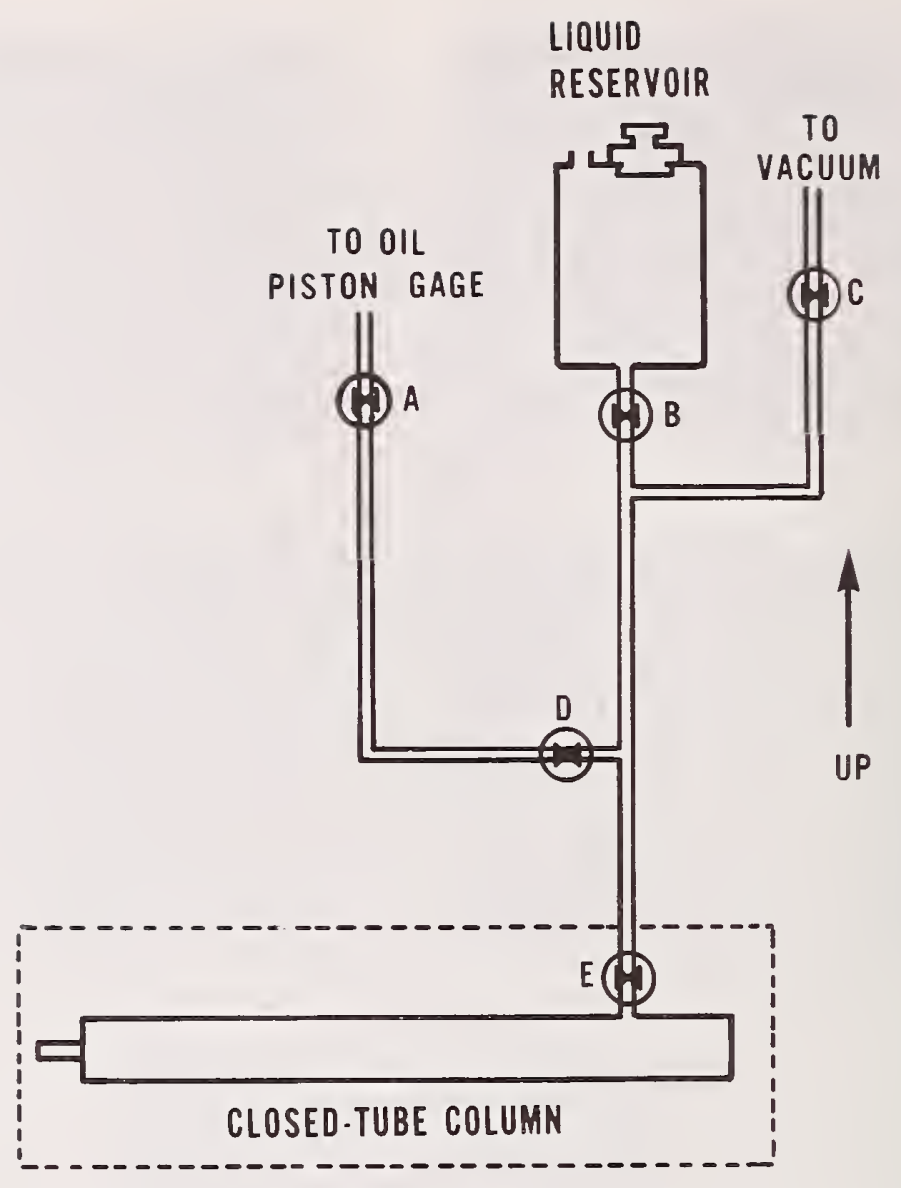

VALVE POSTION CHART

\begin{tabular}{|l|c|c|c|c|c|}
\hline & A & B & C & D & E \\
\hline \hline Step & & & & & \\
\hline Evacuate System & closed & closed & open & open & open \\
\hline Fill System & closed & open ${ }^{2}$ & closed 1 & open & open \\
\hline Pressurize System & open 2 & closed & closed & open & open \\
\hline $\begin{array}{l}\text { Close Calibrator Valve } \\
\text { Yont Oil Piston Gage }\end{array}$ & open & closed & closed & open & closed \\
\hline $\begin{array}{l}\text { Close Down System } \\
\text { Invert; Empty Mercury } \\
\text { Reservoir }\end{array}$ & open & closed & closed & open & closed \\
\hline
\end{tabular}

Figure 12. Schematic elevation of apparatus used to fill closed-tube column. Valves in the filling system are indicated by (A), $(B),(C)$, and (D). Valve (E) is the column valve. The filling procedure, incorporating the sequence of valve operations given in the chart, is described in the text. Numbers 1 and 2 refer to the sequence of valve operation within the step. 


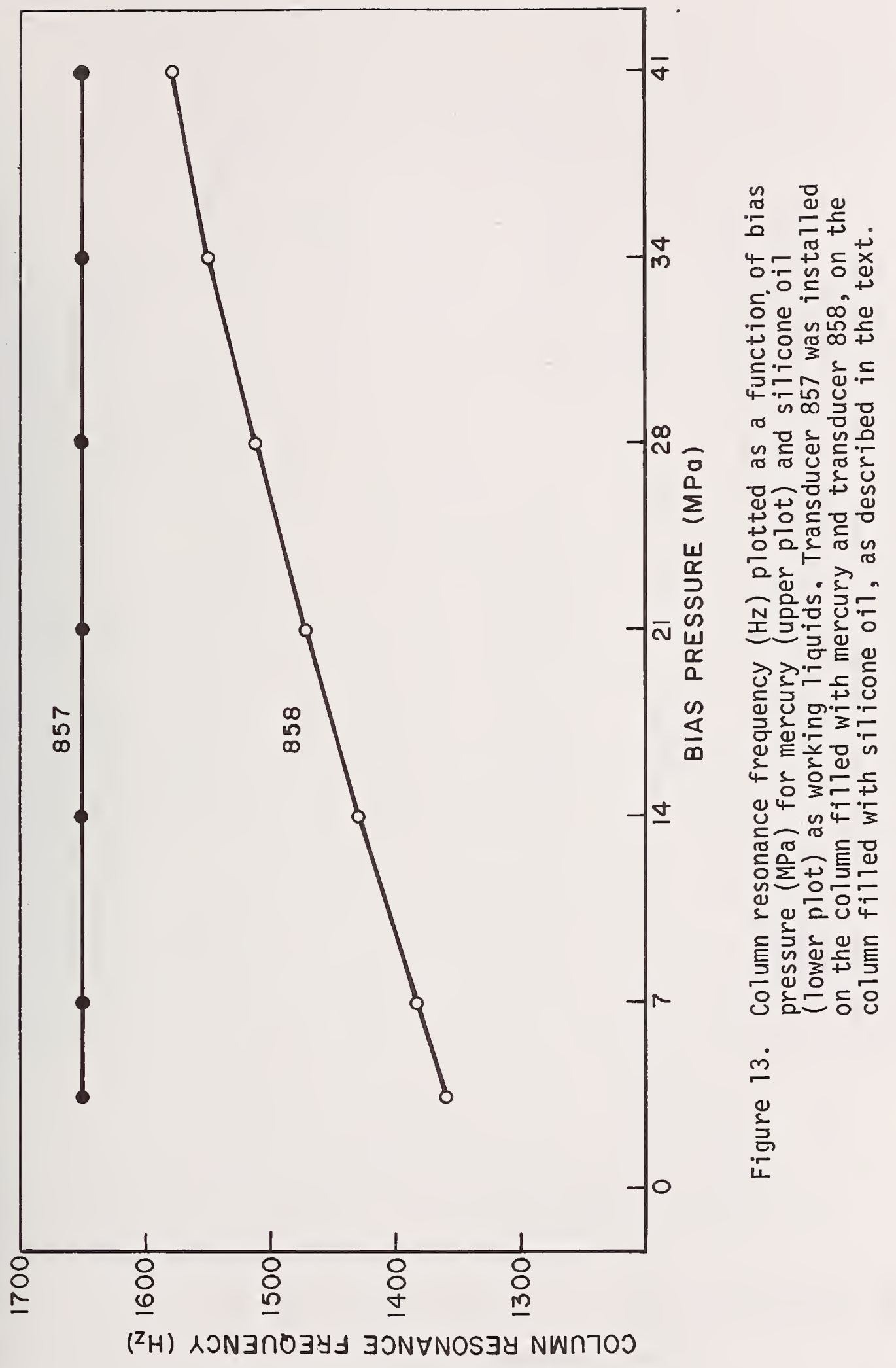




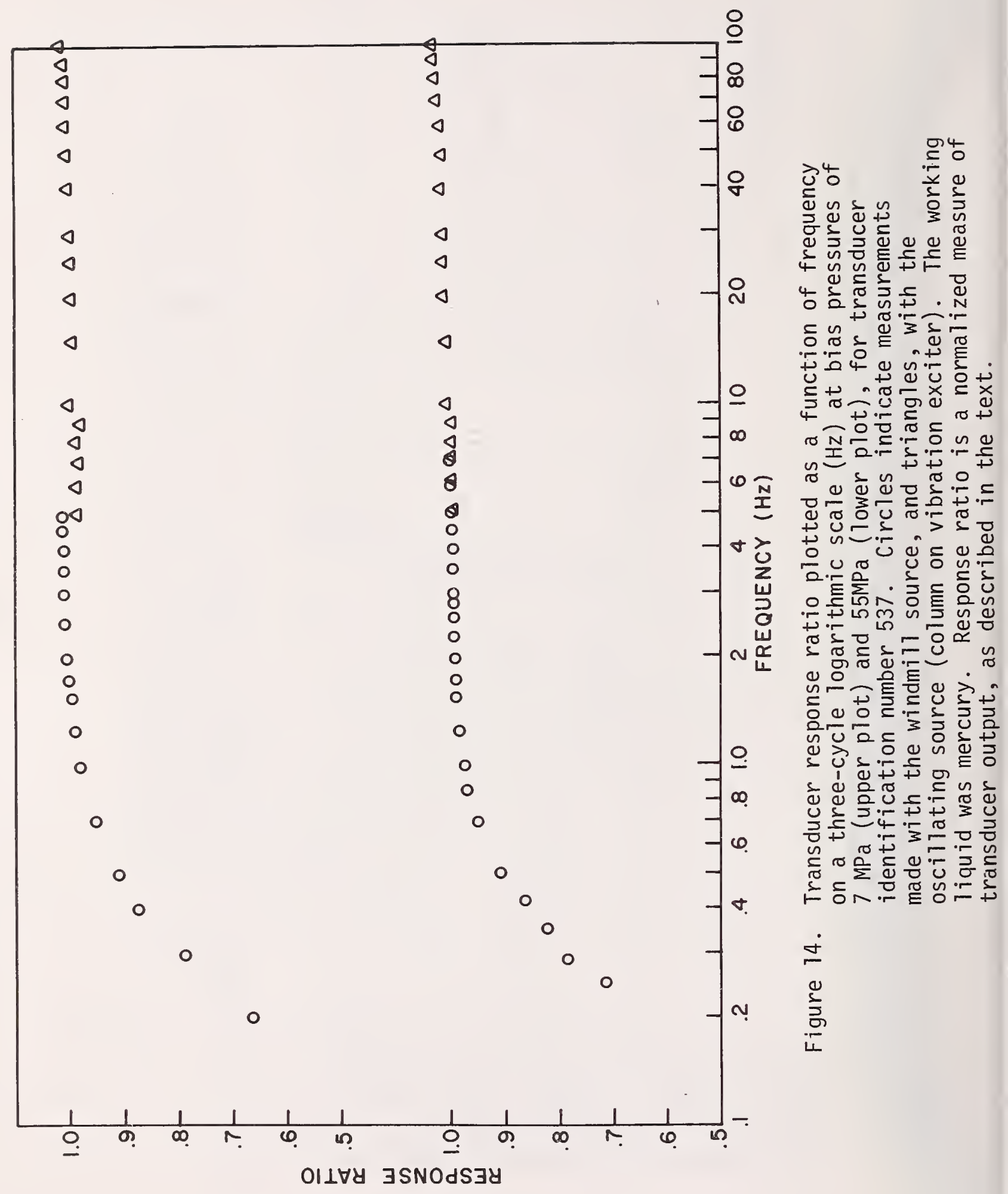




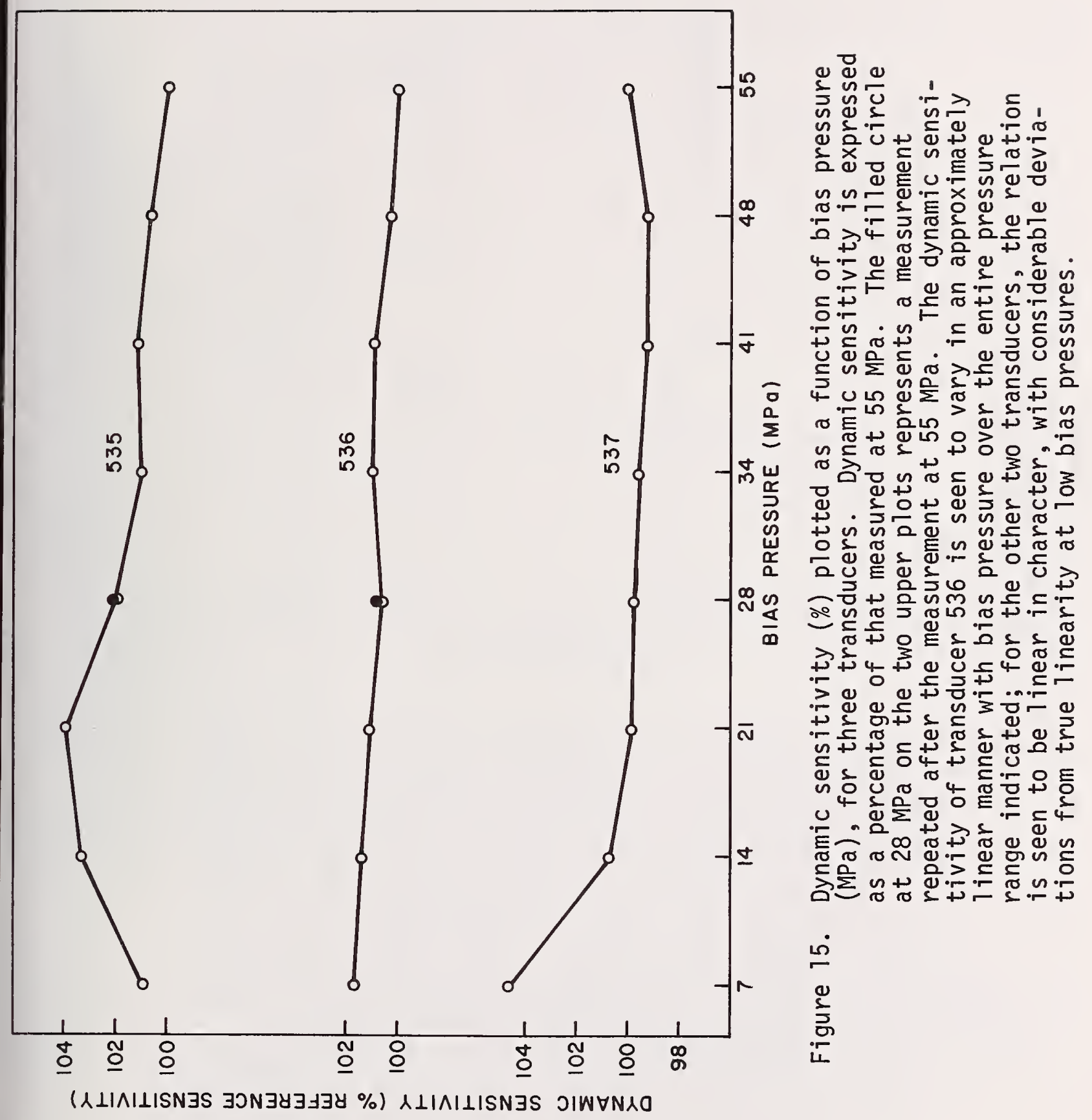




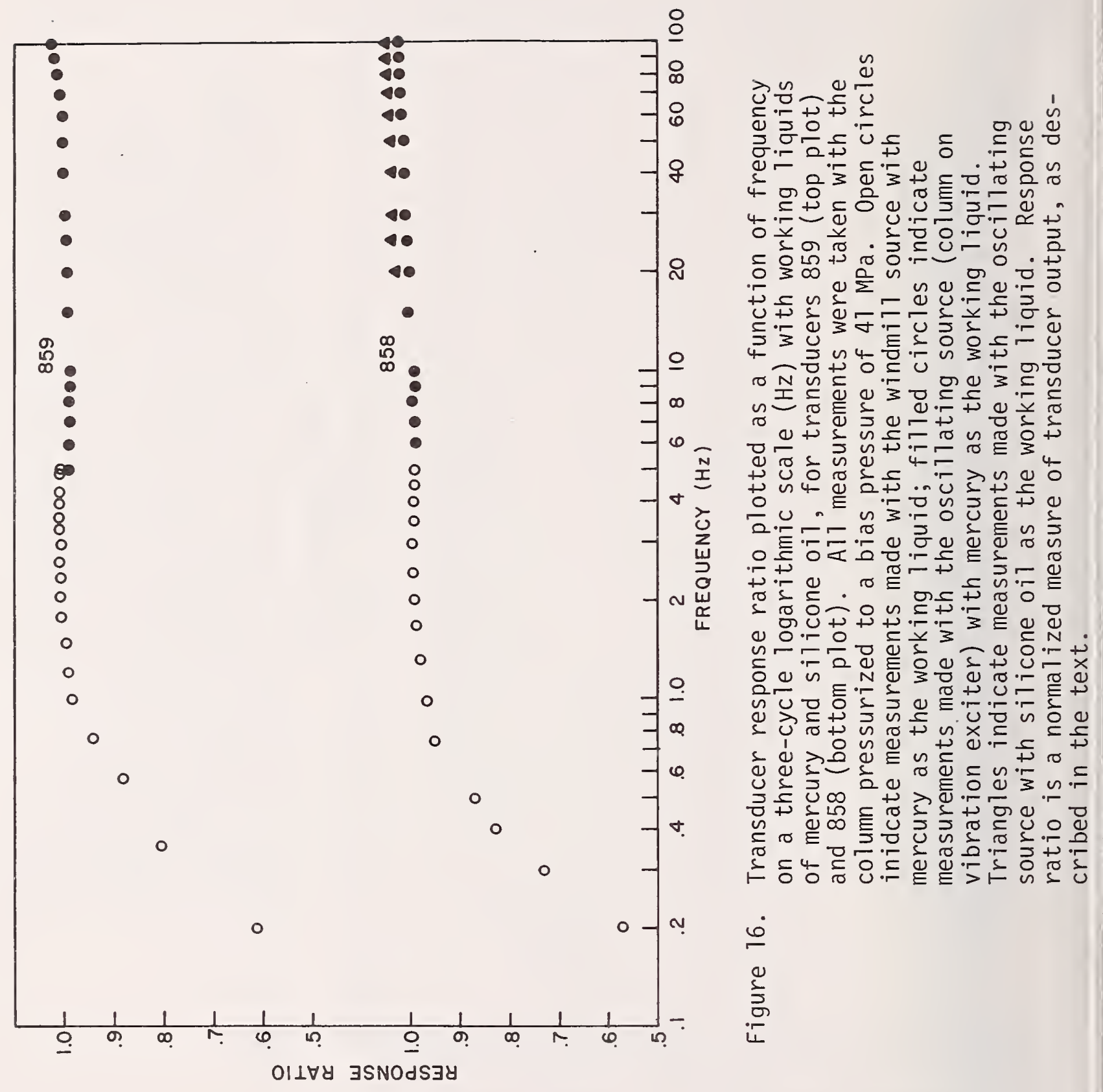




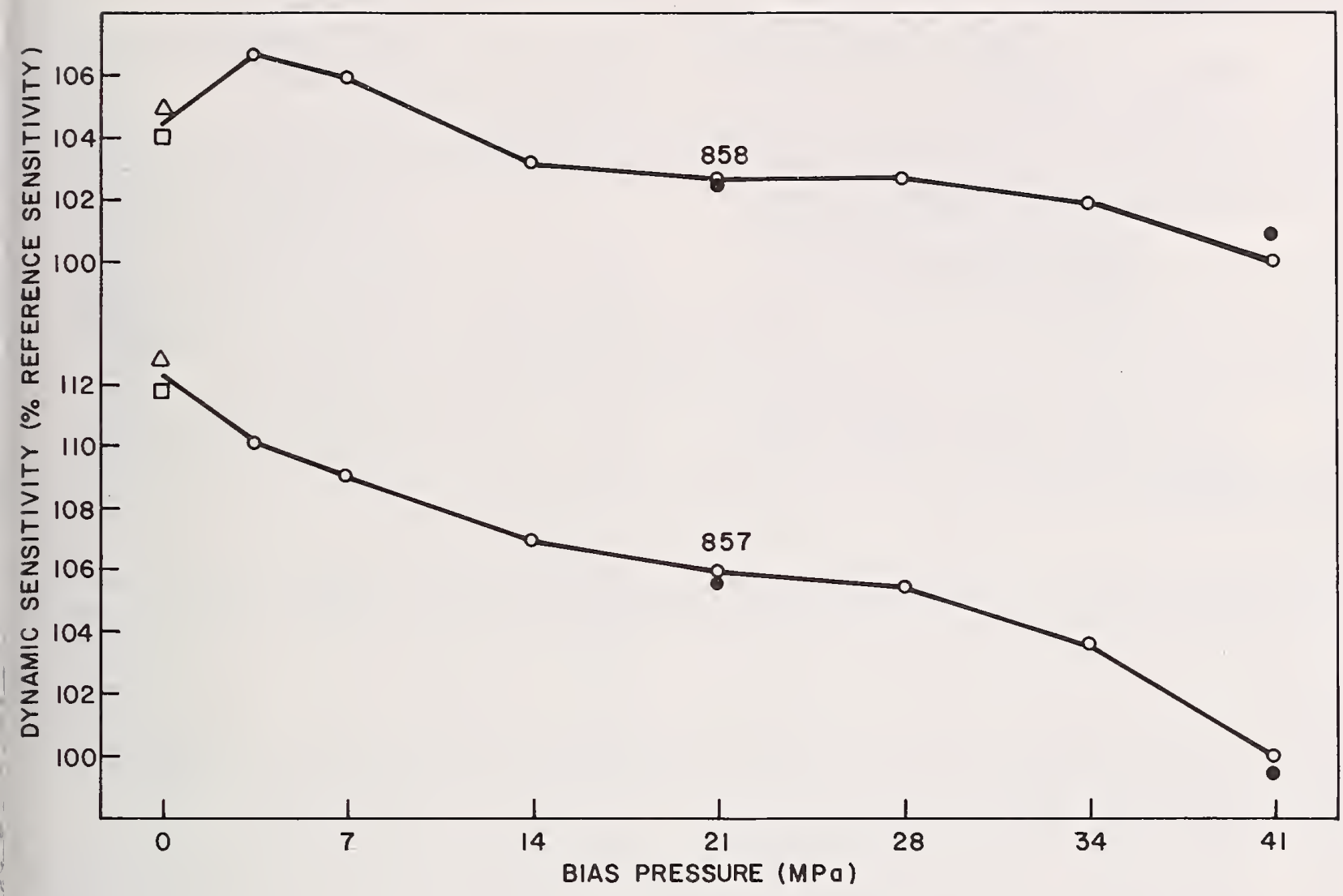

Figure 17. Dynamic sensitivity (\%) plotted as a function of bias pressure ( $\mathrm{MPa}$ ), for transducers 858 (top plot) and 857 (bottom plot). Dynamic sensitivity is expressed as a percentage of that measured at $41 \mathrm{MPa}$. The data points at zero bias pressure are from measurements with a quick-opening-valve apparatus (squares) and with the open-tube dynamic pressure source (triangles). The other data points were taken with the oscillating source (column on vibration exciter). The filled circles at 21 and $41 \mathrm{MPa}$ on each plot represent repeated measurements, the second measurement at $21 \mathrm{MPa}$ follwoing the first at $41 \mathrm{MPa}$, and the second measurement at $41 \mathrm{MPa}$ following the second at $21 \mathrm{MPa}$. As with the plots of figure 15, the general character of the plots is seen to be linear. The agreement at zero bias pressure with the other data is particularly noteworthy in the case of transducer 857. 
HES-114A (REV. 7.73)

\begin{tabular}{|c|c|c|}
\hline $\begin{array}{l}\text { U.S. DEPT. OF COMM. } \\
\text { BIBLIOGRAPHIC DATA } \\
\text { SHEET }\end{array}$ & $\begin{array}{l}\text { 1. PUBLICATION OR REPORT NO. } \\
\text { TN }-927\end{array}$ & 3. Recipient's Accession No. \\
\hline \multirow{2}{*}{\multicolumn{2}{|c|}{$\begin{array}{l}\text { 4. TITLE AND SUBTITLE } \\
\text { Development of Dynamic Calibration Methods for Pogo } \\
\text { Pressure Transducers }\end{array}$}} & $\begin{array}{r}\text { 5. Publication Date } \\
\text { November } 1976\end{array}$ \\
\hline & & 6. Performing Organization Code \\
\hline $\begin{array}{l}\text { 7. AUTHOR(S) John S. } \\
\text { and J.Frankl }\end{array}$ & $\begin{array}{l}1 \text { ten, Paul S. Lederer, Carol F. Vezzetti, } \\
\text { Mayo-Wells }\end{array}$ & 8. Performing Organ. Report No. \\
\hline \multirow{2}{*}{\multicolumn{2}{|c|}{$\begin{array}{l}\text { 9. PERFORMING ORGANIZATION NAME AND ADDRESS } \\
\text { NATIONAL BUREAU OF STANDARDS } \\
\text { DEPARTMENT OF COMMERCE } \\
\text { WASHINGTON, D.C. } 20234\end{array}$}} & $\begin{array}{l}\text { 10. Project/Task/Work Unit No. } \\
4253448\end{array}$ \\
\hline & & $\begin{array}{l}\text { 11. Contract/Grant No. } \\
\text { NASA Order \#H92100A }\end{array}$ \\
\hline \multirow{2}{*}{\multicolumn{2}{|c|}{$\begin{array}{l}\text { 12. Sponsoring Organization Name and Complete Address (Street, City, State, ZIP) } \\
\text { National Aeronautics and Space Administration } \\
\text { G. C. Marshall Space Flight Center } \\
\text { Huntsville, Alabama } 35812\end{array}$}} & $\begin{array}{l}\text { 13. Type of Report \& Period } \\
\text { Covered } \\
\text { Final }\end{array}$ \\
\hline & & 14. Sponsoring Agency Code \\
\hline
\end{tabular}

16. ABSTRACT (A 200-word or less factual summary of most significant information. If document includes a significant bibliography or literature survey, mention it here.)

Two dynamic pressure sources are described for the calibration of pogo pressure transducers used to measure oscillatory pressures generated in the propulsion system of the space shuttle. Rotation of a mercury-filled tube in a vertical plane at frequencies below $5 \mathrm{~Hz}$ generates sinusoidal pressures up to $48 \mathrm{kPa}$, peak-to-peak; vibrating the same mercury-filled tube sinusoidally in the vertical plane extends the frequency response from $5 \mathrm{~Hz}$ to 100 $\mathrm{Hz}$ at pressures up to $140 \mathrm{kPa}$, peak-to-peak. The sinusoidal pressure fluctuations can be generated by both methods in the presence of high pressure (bias) up to $55 \mathrm{MPa}$.

Calibration procedures are given in detail for the use of both sources. The dynamic performance of selected transducers was evaluated using these procedures; the results of these calibrations are presented. Calibrations made with the two sources near $5 \mathrm{~Hz}$ agree to within $3 \%$ of each other.

17. KEY WORDS (six to twelve entries; alphabetical order; capitalize only the first letter of the first key word unless a proper name; separated by semicolons)

Bias pressure; calibration; dynamic calibration; dynamic pressure; high pressure;

liquid medium; pogo pressure; pressure source; pressure transducer; sinusoidal; space shuttle; transducer.

18. AVAILABILITY $x$ Unlimited

For Official Distribution. Do Not Release to NTIS

$\mathrm{X}$ Order From Sup. of Doc., U.S. Government Printing Office Washington, D.C. $20402, \mathrm{SD}$ Cat. No.C13.46:927

Order From National Technical Information Service (NTIS) Springfield, Virginia 22151

\begin{tabular}{|l|c|}
\hline $\begin{array}{l}\text { 19. SECURITY CLASS } \\
\text { (THIS R EPURT) }\end{array}$ & $\begin{array}{c}\text { 21. NO. OF PAGES } \\
\text { UNCLASSIFIED }\end{array}$ \\
\hline $\begin{array}{l}\text { 20. SECURITY CLASS } \\
\text { (THIS PAGE) }\end{array}$ & $\begin{array}{c}\text { 22. Price } \\
\$ 1.15\end{array}$ \\
UNCLASSIFIED & \\
\hline
\end{tabular}




\section{PERIODICALS}

JOURNAL OF RESEARCH reports National Bureau of Standards research and development in physics, mathematics, and chemistry. It is published in two sections, available separately:

- Physics and Chemistry (Section A)

Papers of interest primarily to scientists working in these fields. This section covers a broad range of physical and chemical research, with major emphasis on standards of physical measurement, fundamental constants, and properties of matter. Issued six times a year. Annual subscription: Domestic, $\$ 17.00$; Foreign, \$21.25.

- Mathematical Sciences (Section B)

Studies and compilations designed mainly for the mathematician and theoretical physicist. Topics in mathematical statistics, theory of experiment design, numerical analysis, theoretical physics and chemistry, logical design and programming of computers and computer systems. Short numerical tables. Issued quarterly. Annual subscription: Domestic, $\$ 9.00$; Foreign, $\$ 11.25$.

DIMENSIONS/NBS (formerly Technical News Bulletin)-This monthly magazine is published to inform scientists, engineers, businessmen, industry, teachers, students, and consumers of the latest advances in science and technology, with primary emphasis on the work at NBS. The magazine highlights and reviews such issues as energy research, fire protection, building technology, metric conversion, pollution abatement, health and safety, and consumer product performance. In addition, it reports the results of Bureau programs in measurement standards and techniques, properties of matter and materials, engineering standards and services, instrumentation, and automatic data processing. Annual subscription: Domestic, $\$ 9.45$; Foreign, $\$ 11.85$.

\section{NONPERIODICALS}

Monographs-Major contributions to the technical literature on various subjects related to the Bureau's scientific and technical activities.

Handbooks-Recommended codes of engineering and industrial practice (including safety codes) developed in cooperation with interested industries, professional organizations, and regulatory bodies.

Special Publications-Include proceedings of conferences sponsored by NBS, NBS annual reports, and other special publications appropriate to this grouping such as wall charts, pocket cards, and bibliographies.

Applied Mathematics Series-Mathematical tables, manuals, and studies of special interest to physicists, engineers, chemists, biologists, mathematicians, computer programmers, and others engaged in scientific and technical work.

National Standard Reference Data Series-Provides quantitative data on the physical and chemical properties of materials, compiled from the world's literature and critically evaluated. Developed under a world-wide program coordinated by NBS. Program under authority of National Standard Data Act (Public Law 90-396).
NOTE: At present the principal publication outlet for these data is the Journal of Physical and Chemical Reference Data (JPCRD) published quarterly for NBS by the American Chemical Society (ACS) and the American Institute of Physics (AIP). Subscriptions, reprints, and supplements available from ACS, 1155 Sixteenth St. N.W., Wash. D. C. 20056.

Building Science Series-Disseminates technical information developed at the Bureau on building materials, components, systems, and whole structures. The series presents research results, test methods, and performance criteria related to the structural and environmental functions and the durability and safety characteristics of building elements and systems.

Technical Notes-Studies or reports which are'complete in themselves but restrictive in their treatment of a subject. Analogous to monographs but not so comprehensive in scope or definitive in treatment of the subject area. Often serve as a vehicle for final reports of work performed at NBS under the sponsorship of other government agencies.

Voluntary Product Standards-Developed under procedures published by the Department of Commerce in Part 10, Title 15, of the Code of Federal Regulations. "The purpose of the standards is to establish nationally recognized requirements for products, and to provide all concerned interests with a basis for common understanding of the characteristics of the products. NBS administers this program as a supplement to the activities of the private sector standardizing organizations.

Consumer Information Series-Practical information, based on NBS research and experience, covering areas of interest to the consumer. Easily understandable language and illustrations provide useful background knowledge for shopping in today's technological marketplace.

Order above NBS publications from: Superintendent of Documents, Government Printing Office, Washington, D.C. 20402.

Order following NBS publications-NBSIR's and FIPS from the National Technical Information Services, Springfield, Va. 22161.

Federal Information Processing Standards Publications (FIPS PUBS)-Publications in this series collectively constitute the Federal Information Processing Standards Register. Register serves as the official source of information in the Federal Government regarding standards issued by NBS pursuant to the Federal Property and Administrative Services Act of 1949 as amended, Public Law 89-306 (79 Stat. 1127), and as implemented by Executive Order 11717 (38 FR 12315, dated May 11, 1973) and Part 6 of Title 15 CFR (Code of Federal Regulations).

NBS Interagency Reports (NBSIR)-A special series of interim or final reports on work performed by NBS for outside sponsors (both government and non-government). In general, initial distribution is handled by the sponsor; public distribution is by the National Technical Information Services (Springfield, Va. 22161) in paper copy or microfiche form.

\section{BIBLIOGRAPHIC SUBSCRIPTION SERVICES}

The following current-awareness and literature-survey bibliographies are issued periodically by the Bureau:

Cryogenic Data Center Current Awareness Service. A literature survey issued biweekly. Annual subscription: Domestic, $\$ 20.00 ;$ Foreign, $\$ 25.00$.

Liquified Natural Gas. A literature survey issued quarterly. Annual subscription: $\$ 20.00$.
Superconducting Devices and Materials. A literature survey issued quarterly. Annual subscription: $\$ 20.00$. Send subscription orders and remittances for the preceding bibliographic services to National Bureau of Standards, Cryogenic Data Center (275.02) Boulder, Colorado 80302. 

COM-215

Penalty for Private Use. \$300

SPECIAL FOURTH-CLASS RATE BOOK

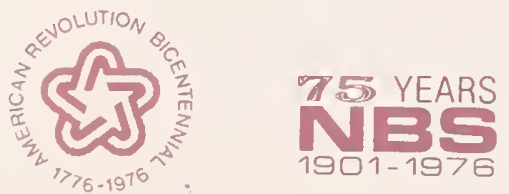

